\title{
FIRST INTERIM STATUS REPORT: MODEL 9975 LIFE EXTENSION PACKAGE TESTING
}

\author{
W. L. Daugherty \\ T. M. Stefek \\ Savannah River National Laboratory \\ Materials Science \& Technology
}

Publication Date: December 2009

\section{Savannah River Nuclear Solutions}

\section{Savannah River Site}

Aiken, SC 29808

This document was prepared in conjunction with work accomplished under

Contract No. DE-AC09-08SR22470 with the U.S. Department of Energy. 


\section{DISCLAIMER}

This work was prepared under an agreement with and funded by the U.S. Government. Neither the U. S. Government or its employees, nor any of its contractors, subcontractors or their employees, makes any express or implied: 1 . warranty or assumes any legal liability for the accuracy, completeness, or for the use or results of such use of any information, product, or process disclosed; or 2. representation that such use or results of such use would not infringe privately owned rights; or 3. endorsement or recommendation of any specifically identified commercial product, process, or service. Any views and opinions of authors expressed in this work do not necessarily state or reflect those of the United States Government, or its contractors, or subcontractors. 


\section{First Interim Status Report - Model 9975 Life Extension Package Testing}

\section{APPROVALS:}

W. L. Daugherty

Date

Author, Materials Science and Technology

T. M. Stefek

Date

Author, Materials Science and Technology

T. E. Skidmore

Date

Technical Review, Materials Science and Technology

K. A. Dunn

Date

Pu Surveillance Program Lead, Materials Science and Technology

G. T. Chandler

Date

Manager, Materials App \& Process Tech

E. R. Hackney

Date

NMM Engineering

\section{REVIEWS:}

J. L. Murphy

Date

Savannah River Packaging Technology 


\section{Revision Log}

$\begin{array}{lll}\text { Document No. } & \text { SRNL-TR-2009-00439 Rev. No. } 0\end{array}$

Document Title $\quad$ First Interim Status Report - Model 9975 Life Extension

Package Testing

Rev. \# Page \# Description of Revision Date

$\begin{array}{lll}0 & \text { all } & \text { Original document } 12 / 29 / 2009\end{array}$ 


\section{$\underline{\text { Summary }}$}

Three 9975 packages have been instrumented and exposed to bounding storage conditions to help identify the extent to which laboratory test results for fiberboard, O-rings and other components apply within a full-scale package. To date, changes observed in the fiberboard overpack and Oring seals are generally consistent with the behavior of laboratory samples. The lead shield within each package has developed a corrosion layer of lead carbonate, consistent with other 9975 packages. However, the morphology of the corrosion layer is different within these packages, possibly as a result of the severity of the conditioning environments beyond normal service conditions.

Conditioning of the second package, LE2, has been discontinued due to the degree of degradation of the fiberboard, and its components have received a final examination. Additional testing will be performed on samples removed from the fiberboard assembly to verify its final condition. The other two packages will continue in test.

\section{Background}

This is an interim status report for experiments carried out per Task Technical Plan WSRC-TR2005-00014 [1], which is part of the comprehensive 9975 package surveillance program [2]. The primary goal of this task is to validate aging models currently under development based on lab scale testing of the fiberboard overpack and containment vessel O-rings. A secondary goal is to examine the behavior of the lead shielding under bounding conditions. This task provides an integrated assessment of the package response to environmental extremes, and demonstrates the extent to which data from small samples scale up to a full package.

Three 9975 packages have been modified to provide instrumentation for monitoring package response and performance to environmental aging. Each package has a different environmental exposure history.

\section{Experimental Method}

The life extension packages are 9975 packages that have been modified with the addition of temperature instrumentation, access ports for fiberboard sample removal and other instrumentation lines, and to provide a heat source internal to the PCV. Two of the three modified packages also have a view port added to the side wall. Thermocouples provide the temperature at a number of locations throughout the package, including the 3013 payload, PCV, SCV, multiple locations within the fiberboard, and drum surface. A sketch showing thermocouple locations is provided in Figure 1.

Each package is placed within a specific environment (controlled external temperature and/or humidity) with an internal cartridge heater providing up to 19 watts. The PCV and SCV were modified to allow placement of a cartridge heater through the bottom of the containment vessels and into a well in the 3013 . The 3013 was welded shut with a surrogate load of steel shot. The cartridge heater conductors and thermocouples attached to the 3013, PCV and SCV exit the package opposite the side where the fiberboard is instrumented, to minimize disruption of the 
measured fiberboard thermal profile. The first package has a humidity probe inserted through the drum sidewall and fiberboard (see Figure 1 for location). Its tip touches the shield. The active sensor region extends from $\sim 1 / 2$ to $1 \frac{1 / 4}{4}$ inch from the tip.

The first package (LE1) is conditioned in an environmental chamber. In the first phase of testing (LE1a), this package was held at constant temperature of $90^{\circ} \mathrm{F}$, with 3 successive humidity levels of 10, 65 and $95 \%$ RH. Each humidity level was held for approximately 6 weeks. The internal cartridge heater was off during this phase to provide a uniform temperature throughout the package. The purpose of this phase was to demonstrate the degree to which the external humidity had an impact on the package interior. In the second phase (LE1b), the package was exposed to an external environment of $142^{\circ} \mathrm{F}$ and $80 \%$ relative humidity. The internal cartridge heater was set to provide a mean fiberboard temperature close to $160^{\circ} \mathrm{F}$. At this temperature, the moisture level of the external environment (if it were present inside the package) would correspond to $\sim 50 \%$ relative humidity, and the fiberboard performance could be compared to that of laboratory samples conditioned at $160^{\circ} \mathrm{F}$ and $50 \% \mathrm{RH}$. Initially, the cartridge heater was set at 10 watts, but increased to 12 watts after 81 days. The caplugs were removed from the drum for approximately 1 year during the second phase. This period included 48 days operation with the internal heater at 10 watts, and 310 days after increasing the internal heater to 12 watts.

The second package (LE2) was operated with the internal cartridge heater set at 19 watts, and exposed to an external temperature sufficient to produce a maximum fiberboard temperature of $240-250^{\circ} \mathrm{F}$. This temperature $\left(250^{\circ} \mathrm{F}\right)$ is the maximum allowed fiberboard temperature during transportation and storage in KAMS, and corresponds to the maximum conditioning temperature of laboratory samples. The external temperature was provided by enclosing the package in a modified 55 gallon drum, and placing a drum heater around this larger drum. The drum heater setpoint is adjusted as necessary to maintain the desired maximum fiberboard temperature.

After early observations of unexpected behavior in LE2, the third package (LE3) was assembled and operated at a lower temperature to identify the extent to which the observed behaviors might occur in a more realistic KAMS environment. These observations included essentially all the moisture remaining in the fiberboard being driven to the bottom of the package, and a heavy black corrosion product on the shield. Some of the moisture from the fiberboard had initially condensed on the underside of the drum lid (Figure 2) before that moisture was also driven off. After these observations, additional insulation was added to the top of the drum and around the base of the drum heater (for LE2 and LE3), to reduce the degree of heat loss in the axial direction.

The first package has a wetness sensor at the bottom between the fiberboard and drum side wall. This sensor is intended to identify if liquid condensation forms within the package. The second package was not expected to form condensation since it was to be heated only (no humidity control). However, significant moisture was found to have migrated to the bottom of this package. Accordingly, a moisture sensor was added to the instrumentation for the third package.

The second package was initially brought to temperature slowly and incrementally, to avoid an overshoot in fiberboard temperature. It is likely that during this time ( 34 days to reach a fiberboard temperature of $235^{\circ} \mathrm{F}$ ) that significant moisture redistribution was occurring. Most of the moisture in the fiberboard would migrate to the cooler regions of the package (i.e. to the 
bottom of the package). This in turn would decrease the thermal conductivity for the bulk of the fiberboard, and increase the temperature gradient across the fiberboard.

Thermocouple and moisture sensor data from the packages are automatically recorded at preset intervals. Data from the humidity probe in LE1 are manually recorded on a daily basis.

Additional data is collected on an occasional basis during periodic examinations. This includes:

- $\quad$ Photographs of the fiberboard position through the view port in LE1 and LE2

- Weight of the entire package

- Weight and moisture content of the removable fiberboard sections

- Visual observations of the package exterior

- Weight and dimensions of the fiberboard assemblies and shield

- Visual observations of other package components

The last 2 of the above data sources require opening the drum lid and removing multiple internal components. These steps are not performed with every examination, so these data are not collected as often as the other items listed.

\section{$\underline{\text { Results }}$}

There are several metrics which provided evidence of change in the package over time. These include package weight, fiberboard internal humidity (LE1 only), fiberboard position within the view port (LE1 and LE2), and the temperature profile across the fiberboard. Additional indications of change might be seen in the weight and appearance of the removable fiberboard sections, dimensional variation of the lead shield, and from visual observations of the components.

Plots of package weight over time are shown for each package in Figures 3-5. Another key indication of internal change was the humidity reading taken near the fiberboard ID surface for package 1. These data are shown in Figure 6. During a period of approximately 4 months, indicated on Figure 6, the humidity probe was not fully inserted into the fiberboard assembly. This resulted from misalignment of the hole through the fiberboard in relation to the drum penetration following fiberboard shrinkage.

Two small sections of fiberboard were cut from the bottom of each lower assembly, and are accessible to remove through a hatch on the drum side. These sections are characterized more often than the drum is opened to inspect the upper or lower fiberboard assembly. Weight data for these removable sections are shown for each package in Figures 7-9. Their moisture content is summarized in Table 1.

Photographs of the removable sections help to track fiberboard changes over time. Sequences of photographs for each package are shown in Figures 10-12. In test LE1, the appearance of the removable sections remains relatively uniform, although they darken somewhat over time. A strong odor was noted from the removable sections after 14 weeks at $142^{\circ} \mathrm{F}$ ambient, and continued during subsequent inspections. The peak moisture content of the removable sections ranged from 13 to $30 \% \mathrm{WME}$ through the first 57 weeks at $142^{\circ} \mathrm{F}$ ambient, and increased to $100 \% \mathrm{WME}$ at week 63. At no time was mold observed on the LE1 fiberboard. The removable sections for LE1 would have been at a temperature close to the external environment $\left(142^{\circ} \mathrm{F}\right)$. 
With tests LE2 and LE3, the bottom layers of the removable sections (as well as the rest of the lower fiberboard assembly) darkened significantly as they accumulated excess moisture. Some mold also grew in this region. In LE2, the bottom layers were observed to be saturated during the first inspection (after 3 weeks at temperature, 8 weeks total exposure), and a strong odor of decaying vegetation was noted after 19 weeks in test. Mold did not appear on the test 2 removable sections until 63 weeks exposure. A steep moisture gradient existed at the bottom of LE2; the saturated layers had a moisture content of $100 \% \mathrm{WME}$, while approximately $1 / 2$ inch above this region the moisture content was typically $17 \% \mathrm{WME}$ or less.

In LE3, mold was observed after 5 weeks exposure. At this time, the moisture content of the LE3 removable sections ranged from $67 \% \mathrm{WME}$ in the bottom layer to $12 \% \mathrm{WME}$ in the top layer. The moisture content of the bottom layer increased to $100 \% \mathrm{WME}$ at 15 weeks exposure. The mold continued to grow during subsequent exposure. During examination after 45 weeks exposure, the moisture content of the lower removable section at the maximum height of mold growth was $20 \% \mathrm{WME}$. The temperature of the removable sections within the conditioning environment is unknown for test packages LE2 and LE3.

The drums for tests LE1 and LE2 were modified to include a view port on the side. A pattern was marked on the lower fiberboard assemblies to be viewed through the view port, and identify the extent to which the fiberboard moved. Typical photographs of this pattern through the view port are shown in Figures 13 and 14. In all cases, the overall fiberboard height was reduced, as indicated by the pattern shifting downward. Measurements were made from photographs taken at each inspection interval to estimate the amount of fiberboard movement. These measurements are summarized in Figures 15 and 16.

After 19 weeks in test (96 days at temperature), dimensional measurements were made on test 2 to determine whether an axial gap had opened between the upper and lower fiberboard assemblies. At this time, the fiberboard visible at the upper edge of the window had dropped by 0.98 inch. Calculations indicated that a vertical gap of approximately 0.6 inch existed between the two assemblies, but this value is based on assumptions regarding the uniformity of shrinkage over the height of each assembly. Both fiberboard assemblies and the shield were measured after 81 weeks exposure. Based on these final measurements, a vertical gap of 1.19 inches had opened between the two assemblies. The fiberboard had dropped a total of 1.8 inches at the top edge of the window at this time.

The fiberboard assemblies from package LE1 were measured after 57 weeks exposure at $142^{\circ} \mathrm{F}$. Based on these measurements, there was no vertical gap between fiberboard assemblies. Rather, a gap of 0.02 inch remained between the shield lid and upper assembly bearing plate. Data are not yet available to perform a similar calculation for LE3.

In order to increase the likelihood that package LE1 could gain moisture from its environment $\left(142^{\circ} \mathrm{F}, 80 \% \mathrm{RH}\right)$, the caplugs were removed from that package for approximately 1 year. The test used an internal heat source of 10 watts for 33 days with the caplugs in place, and then an additional 48 days with the caplugs removed. The heat source was then increased to 12 watts (to increase the fiberboard temperatures) and run for 310 days with the caplugs removed. The caplugs 
were then re-installed and the package tested for an additional 137 days. The package weight changes for these different conditions are summarized in Table 2.

Given the relatively low melting temperature of lead $\left(621^{\circ} \mathrm{F}\right)$, the shield may experience creep at service temperatures. Measurements of the LE2 shield were analyzed to investigate this possibility, and are summarized in Table 3. Since the other packages were operated at lower temperature, they are less likely to experience creep within the exposure periods to date.

The corrosion of the lead shields is also of interest. In LE2, the corrosion product was observed during the first inspection, after 19 weeks in test, and was dark gray / black and nodular (Figure 17). Significant corrosion product was slower to develop on the LE1 shield, but was similar in appearance (Figure 18). In contrast, the corrosion product on LE3 remained white, but did develop occasional nodules (Figure 19). Of these three cases, the corrosion product on LE3 is the closest in appearance to that typically seen on 9975 packages (smooth white surface). Chemical analysis of corrosion product collected from LE2 showed that it was generally consistent with the lead carbonate seen on other packages.

Each package contains a number of thermocouples throughout the fiberboard to monitor the temperature gradient. For each package, the hottest measured temperature within the fiberboard is at the highest elevation on the ID surface, and the coolest measured temperature within the fiberboard is at the lowest elevation on the OD surface. The temperature vs time data at the highest fiberboard ID and lowest fiberboard OD locations are summarized in Figure 20 for each package. It is likely that the fiberboard reached slightly higher temperatures at elevations above the uppermost ID thermocouple. However, the variation among the 4 thermocouples along the ID surface in the central region adjacent to the shield shows a modest gradient $\left(\sim 6^{\circ} \mathrm{F}\right.$ for LE2, $\sim 2^{\circ} \mathrm{F}$ for LE3) for each package. Therefore, the recorded temperatures are assumed to provide a reasonable approximation of the maximum fiberboard conditions.

Along the OD surface, the four thermocouples indicate a vertical gradient approximately 5 times higher than along the ID surface for packages LE2 and LE3, and a vertical gradient similar to that along the ID surface for LE1 $\left(1-2^{\circ} \mathrm{F}\right)$. The excess moisture at the bottom of packages LE2 and LE3 suggests that a relatively steep temperature gradient exists within the bottom several inches.

There are a number of periods of temperature transients for each package associated with inspections, power outages, etc. To better illustrate possible changes of the fiberboard thermal properties, the fiberboard temperature profile is examined at select periods of steady state operation. The temperature profile across the sidewall of the fiberboard is plotted in Figure 21 for each package.

Based on the degradation of LE2 fiberboard and the air shield becoming detached from the upper fiberboard assembly, it was decided that the package would not return to test. Accordingly, the LE2 SCV and PCV received a final leak test, and each vessel was opened to examine the O-rings. The leak test on each vessel interrogated both O-rings, and the measured leak rate met the acceptance criterion of <2.0 E-7 std cc He/sec. O-ring measurements were taken at several intervals after the vessels were opened. The first measurements are based on photographs of the O-rings still installed on the cone seal plug taken 5 minutes after opening. Subsequent 
measurements were taken with a snap gage after the O-rings were removed, at periods of $<30$ minutes, 9 days and 30 days after opening. Compression set of each O-ring is calculated based on each of these measurement periods. Results are summarized in Table 4.

\section{$\underline{\text { Discussion }}$}

Package LE2 experienced the most extreme environment, and exhibited the most extreme response. The component temperatures created by this environment (e.g. near $250^{\circ} \mathrm{F}$ maximum fiberboard temperature) are higher than expected in KAMS, but are consistent with conditions allowed by the KAMS safety basis for storage and the SARP for transport. Significant changes in LE2 were observed during the first inspection after 9 weeks in test ( 3 weeks at temperature), including:

- The bottom fiberboard layers ( 1 inch) were saturated with water, and very little moisture remained in the fiberboard above.

- $\quad$ The fiberboard shrank axially, evidenced by a drop of $\sim 3 / 4$ inch at the view port.

- When the package was opened after 19 weeks in test, significant corrosion was observed on the shield. This likely began before the 9 week inspection, although the package was not opened at that time to examine the shield.

The other two packages experienced less extreme environments, although still conservative to typical KAMS conditions, and exhibited less extreme responses. All packages experienced a significant re-distribution of moisture within the fiberboard, and changes in fiberboard dimensions. Test LE3, for example, had liquid condensate on the lid and air shield when inspected after 5 weeks in test. It also had mold on the removable fiberboard sections after 5 weeks.

With the ambient temperature for LE1 established by an environmental chamber, the package exterior maintained a more uniform temperature $\left(\sim 142^{\circ} \mathrm{F}\right)$ than the other packages. This package also did not experience any mold growth on the fiberboard. This is likely due to the higher minimum temperature of the package. In contrast, both LE2 and LE3 were heated from the side and were stored on a metal plate. Even with the addition of insulation around the base, the bottom of these 2 packages was probably significantly cooler than at higher elevations. The maximum temperature at which mold will grow on fiberboard is currently not known.

During their last inspections, both packages LE1 and LE2 had the air shield detach from the upper fiberboard assembly. In LE2, it detached with very little force as the assembly was being removed from the package. Several hooks were improvised to pull the upper fiberboard assembly from LE2, leaving significant impressions in the degraded fiberboard. In LE1, the air shield remained attached as the upper assembly was removed, but detached as it was being returned to the package. With the significant changes elsewhere in LE2, this package was not returned to test. LE1 will likely be returned to test. A test plan will be developed for samples removed from the LE2 fiberboard assembly.

Thermal conductivity changes for package LE2 vs laboratory data Package LE2 data were examined for evidence of change in fiberboard thermal conductivity since it operated at the highest temperature and would be expected to show the greatest change. There is a region of relatively constant thermal response among the upper 3 thermocouples on the 
fiberboard ID and OD surfaces. The temperature along either surface varies little within this region during steady state operation. This region will be the primary focus in examining any change in thermal properties. Since some heat is lost through the top and bottom of the package, the heat conducting through this side region will be less than 19 watts, but it will be assumed constant over time.

Thermal gradient information was examined at several discrete times during periods of steady state operation indicated by the arrows in Figure 22. The thermal conductivity will vary with changes in the temperature gradient and fiberboard thickness, as described by:

$\mathrm{q} / \mathrm{A}=\mathrm{k} * \Delta \mathrm{T} / \mathrm{t}$

where, $\mathrm{q} / \mathrm{A}=$ heat flux (assumed constant)

$\mathrm{k}=$ thermal conductivity

$\Delta \mathrm{T}=$ radial temperature gradient

$\mathrm{t}=$ lower assembly radial thickness (linear interpolation based on available inspection data)

At each of the arrows in Figure 22, the radial temperature gradient and lower assembly thickness are combined per this relationship to get a value proportional to the thermal conductivity (see Table 5). The value for the first data point (at 52 days in test, 18 days at temperature) is taken as a reference point, and the values for subsequent data points are normalized to this first data point. (Since the actual heat flux through this region of fiberboard is unknown, the actual thermal conductivity cannot be calculated directly.)

These normalized data are plotted in Figure 23, and show a decrease over time in the thermal conductivity. Data from laboratory sample $2234-\mathrm{R}$ conditioned at $250^{\circ} \mathrm{F}$ are also shown in Figure 23 for comparison. These lab data are normalized to the value interpolated for 18 days at temperature to provide a direct comparison in change for the subsequent behavior. The data based on the LE2 temperature gradients provide an overall reasonable match to the laboratory data.

Fiberboard mass changes vs lab data

Variation in the total weight of each package is summarized in Figures 3-5. Test LE1 experienced several environments, and the rate of weight change varies with each environment. In phase LE1b, the LE1 fiberboard temperature ranged from $\sim 140^{\circ} \mathrm{F}$ (OD surface) to $165^{\circ} \mathrm{F}$ (ID surface). Table 2 shows the rate of package weight loss ranged from 0.001 to $0.004 \% /$ day. If the entire weight loss is attributed to the fiberboard (with a typical fiberboard weight of $31 \mathrm{~kg}$, neglecting the bearing plates and air shield), the overall weight loss rate for the fiberboard is $0.006-0.026 \%$ /day. In comparison, laboratory samples conditioned at $160^{\circ} \mathrm{F}$ and $50 \% \mathrm{RH}$ show weight loss at a rate of 0.008 to $0.02 \% /$ day. Two factors should be considered in comparing the laboratory samples with LE1. Figure 6 indicates that the humidity towards the fiberboard ID surface of LE1 was 50\%, and it increased towards the outer surface. A higher humidity will tend to increase the rate of fiberboard weight loss for a given temperature. In addition, since an increased weight loss rate was observed for LE1 with the caplugs removed, weight loss from the continued slow escape of excess moisture from the drum would be added to any weight loss from fiberboard degradation. 
Package LE2 lost weight at an average rate of $0.004 \%$ /day, with the fiberboard temperature ranging from $\sim 190^{\circ} \mathrm{F}$ (OD surface) to $245^{\circ} \mathrm{F}$ (ID surface). If the entire weight loss is attributed to the fiberboard (with a typical fiberboard weight of $31 \mathrm{~kg}$, neglecting the bearing plates and air shield), the overall weight loss rate for the fiberboard is $0.021 \%$ day. The weight loss of the upper fiberboard assembly from LE2 is shown in Figure 24, with an average rate of fiberboard weight loss of $0.027 \%$ /day (neglecting weight of bearing plate and air shield). The range of temperature data for the LE2 fiberboard suggests a mid-range temperature of $\sim 218^{\circ} \mathrm{F}$. The average temperature at the higher elevations (near the upper assembly) is closer to $235^{\circ} \mathrm{F}$, and the temperature near the bottom of the package is likely significantly cooler than $190^{\circ} \mathrm{F}$ (based on the steep moisture gradient).

In comparison to the LE2 fiberboard data, laboratory samples conditioned at $215^{\circ} \mathrm{F}$ lost weight at an average rate of $\sim 0.01 \%$ dday, while samples conditioned at $250^{\circ} \mathrm{F}$ lost weight at an average rate of $\sim 0.04 \% /$ day. Recognizing that the conditioning temperatures are different, these values are generally consistent with the behavior of LE2.

Package LE3 lost weight at an average rate of $0.001 \%$ /day, with the fiberboard temperature ranging from $\sim 115^{\circ} \mathrm{F}$ (OD surface) to $160^{\circ} \mathrm{F}$ (ID surface). If the entire weight loss is attributed to the fiberboard (with a typical fiberboard weight of $31 \mathrm{~kg}$, neglecting the bearing plates and air shield), the overall weight loss rate for the fiberboard is $0.0072 \% /$ day. As discussed above, laboratory samples conditioned at $160^{\circ} \mathrm{F}$ and $50 \% \mathrm{RH}$ show weight loss at a rate of 0.008 to 0.02 $\% /$ day. Similarly, samples conditioned at $125^{\circ} \mathrm{F}$ (no humidity control, but generally $<10 \% \mathrm{RH}$ ) show seasonal variation in weight, but no net long-term weight loss. The fiberboard weight loss for LE3 would therefore be expected to fall between these two rates for laboratory samples.

\section{Moisture and Fiberboard}

From the Table 2 data on the weight loss of LE1 under different configurations, there are several points of interest regarding moisture loss. First, in spite of an external humidity of $80 \%$, the package lost weight (moisture) for each of the conditions. Since the rate of weight loss was greater with the caplugs removed, at least some of the weight loss is due to moisture loss from the drum. This would indicate that the relative humidity inside LE1 (around the fiberboard OD surface) is greater than $80 \% \mathrm{RH}$.

The relative humidity and temperature were recorded periodically in LE1. Most of the time the probe tip was near the fiberboard ID surface at the base of the shield. For a short period, the probe was not inserted as far into the fiberboard, and readings were taken closer to the fiberboard midradius. Near the fiberboard ID, typical readings were $50 \% \mathrm{RH}$ and $156^{\circ} \mathrm{F}$. Closer to the fiberboard mid-radius, typical readings were $\sim 65 \% \mathrm{RH}$ and $147^{\circ} \mathrm{F}$. Along the fiberboard OD surface, thermocouple readings indicated a temperature of $141-142^{\circ} \mathrm{F}$, and the discussion above suggests a humidity along the OD surface greater than $80 \% \mathrm{RH}$. Based on psychrometric charts [3], the moisture content of air at $156^{\circ} \mathrm{F}$ and $50 \% \mathrm{RH}$ corresponds to $\sim 62 \% \mathrm{RH}$ at $147^{\circ} \mathrm{F}$, and $\sim 73 \% \mathrm{RH}$ at $141^{\circ} \mathrm{F}$. This provides further evidence that a moisture gradient exists within the package, since the humidity at the lower temperatures is greater than indicated for a constant moisture concentration.

With an internal heat source of 10 watts and the caplugs in place, the rate of weight loss in LE1 was greater than with an internal heat source of 12 watts (regardless of caplug configuration). The 
lower overall weight loss rates at 12 watts suggest that the higher heat load might increase the axial moisture gradient such that less moisture is held near the caplug holes.

\section{Potential for Shield Creep}

The data in Table 3 indicate the possibility that creep of the lead shield occurred in LE2, although this conclusion is complicated by the fact that the shield dimensions were also changing due to corrosion. Creep of the lead would be manifested by a reduction in wall thickness at the top of the shield, and an increase in wall thickness near the bottom. The observed corrosion on the shield was generally uniform over the entire surface.

At the top of the LE2 shield, the average radial thickness remained relatively constant (maximum increase of 0.008 inch). In the absence of creep, it would be expected to increase due to the accumulation of corrosion product. In contrast, the average radial thickness at the bottom increased by $0.032-0.034$ inch. Corrosion alone would be expected to produce a similar increase in shield thickness at the top and bottom. It is not obvious why the measured radial thickness (at either top or bottom) is greater after 36 weeks than after 81 weeks, but this may reflect measurement uncertainty.

Using the shield measurements after 81 weeks, if the loss in wall thickness at the top due to creep is assumed equal to the increase in wall thickness at the bottom, then a change in thickness of $\sim 0.014$ inch can be attributed to creep, while corrosion has led to a uniform increase in thickness of $\sim 0.018$ inch. This would correlate to a rate of $(0.014 * 52 / 81=) 0.009$ inch/year change in thickness due to creep. If the shield measurements taken at 36 weeks were used instead, the data would indicate a creep rate of $(0.013 * 52 / 36)=0.02 \mathrm{inch} /$ year.

Literature data can be used to estimate the potential for lead creep based on the temperature and stress in the shield. In LE2, the fiberboard ID surface was typically $240-245^{\circ} \mathrm{F}$. Accordingly a typical shield temperature of $250^{\circ} \mathrm{F}(394 \mathrm{~K})$ will be assumed. With a melting temperature of $621^{\circ} \mathrm{F}$ $(601 \mathrm{~K})$, the shield homologous temperature (temperature / melting temperature) is 0.66 . The stress in the shield is primarily from its own weight. The stainless steel liner will be assumed to carry the weight of the upper fiberboard assembly. It will also provide some reinforcement to the lead, but this effect will be ignored for now. With a shield height of 24.7 inches, the stress on the shield at a height 1 inch from the bottom will be:

$$
\text { Stress }=23.7 \mathrm{in} *\left(708 \mathrm{lb} / \mathrm{ft}^{3}\right) /(12 \mathrm{in} / \mathrm{ft})^{3}=10 \mathrm{psi}(=0.07 \mathrm{MPa})
$$

This value corresponds to a shear stress of $0.04 \mathrm{MPa}$. With a shear modulus of $7300 \mathrm{MPa}$ for lead at $300 \mathrm{~K}$, the normalized shear stress is $5 \mathrm{E}-6$. Reference 4 provides a map of lead creep rates as a function of normalized shear stress and homologous temperature for grain sizes of $10 \mu$ and $1 \mathrm{~mm}$. The grain size of the shield likely falls between these two values. The map indicates a creep rate of 7 E-9 /sec for a grain size of $10 \mu$, and $\sim 1 \mathrm{E}-11$ /sec for a grain size of $1 \mathrm{~mm}$. For the finer grain size, this creep rate converts to $22 \%$ /year, or 0.11 inch/year. For the larger grain size, the shield creep rate would be negligible ( $\sim 0.0002 \mathrm{inch} /$ year). The actual creep rate likely falls between these two values, as suggested by the estimates based on shield measurement data. 


\section{LE2 O-Rings}

The O-rings in LE2 were generally at a temperature of $\sim 265^{\circ} \mathrm{F}(\mathrm{PCV})$ or $\sim 255^{\circ} \mathrm{F}$ (SCV), with a total time at temperature of 461 days. The compression set measured initially upon opening ranged from 58 to $67 \%$. These values are based on measurements taken from photographs of the O-rings still installed on the cone seal plug. Thickness measurements were taken with a snap gage approximately 20 minutes later, giving slightly smaller, but comparable, values. This illustrates the validity of measurements from photographs, which can provide an opportunity to obtain data sooner after opening a vessel. After 30 days, the compression set values had decreased to a range of 26 to 45\%. Data from laboratory testing of O-rings [5] indicates that the compression stress relaxation for a similar exposure $\left(250^{\circ} \mathrm{F}\right.$ for 461 days) would be $\sim 50 \%$. While compression set and compression stress relaxation do not necessarily change at the same rate for a given environment, this comparison does illustrate a degree of consistency between package LE2 and laboratory data.

\section{Conclusions}

Three 9975 packages have been instrumented and exposed to bounding storage conditions to help identify the extent to which laboratory test results for fiberboard, O-rings and other components apply to a full-scale package. Results to date indicate the following:

- With elevated temperature, the fiberboard loses mass (due to pyrolysis) and shrinks. Shrinkage is greatest in the axial direction. In this regard, the three test packages displayed behavior consistent with laboratory samples.

- The fiberboard thermal conductivity decreases over time at elevated temperature. Estimates of the change in thermal conductivity (in the radial direction) for LE2 are consistent with changes seen in laboratory samples conditioned at a similar temperature.

- The lead shield in all three test packages experienced significant corrosion. Each of the three test packages showed a varying corrosion morphology, which differs from that typically seen in 9975 packages. However, analysis of the corrosion product from the LE2 shield identified a composition consistent with the lead carbonate observed on other packages.

- Based on laboratory test data on O-rings to date, failure of the O-rings is not expected for any of the test packages based on conditioning thus far. The O-rings in the LE2 containment vessels remain leak-tight. Upon opening the LE2 containment vessels, the compression set measured initially was $\sim 58 \%$ for the PCV and $\sim 64 \%$ for the SCV. These values are similar to the predicted compression stress relaxation predictions based on laboratory data. O-rings in the other packages have not been re-tested.

Conditioning of package LE2 has been discontinued due to the degree of degradation of the fiberboard. The components, including O-rings, have received a final examination. Additional testing will be performed on samples removed from the fiberboard assembly to verify thermal conductivity and compression strength. The other two packages will continue in test. 


\section{$\underline{\text { References }}$}

[1] WSRC-TR-2005-00014, Rev. 2, "Task Technical and Quality Assurance Plan for Full-Scale Testing of Model 9975 Packages to Support Life Extension Model Development (U)”, June 2008.

[2] WSRC-TR-2001-0286, Rev. 2, "SRS Surveillance Program for Storage of Pu Material in KAMS”.

[3] Perry’s Chemical Engineers’ Handbook, 6 ${ }^{\text {th }}$ Edition, McGraw-Hill 1984

[4] “Deformation-Mechanism Maps, The Plasticity and Creep of Metals and Ceramics”, H. J. Frost (Dartmouth College) and M. F. Ashby (Cambridge University), web version http://engineering.dartmouth.edu/defmech/

[5] SRNS-TR-2009-00259, “Lifetime Prediction for Model 9975 O-Rings in KAMS”, E. N. Hoffman and T. E. Skidmore, November 2009

Table 1. Moisture content of removable fiberboard sections

\begin{tabular}{|c|c||c|c||c|c|}
\hline \multicolumn{2}{|c||}{ LE 1B } & \multicolumn{2}{c||}{ LE 2 } & \multicolumn{2}{c|}{ LE 3 } \\
\hline $\begin{array}{c}\text { Time } \\
\text { days })\end{array}$ & $\begin{array}{c}\text { Moisture } \\
\text { Content } \\
(\% W M E)\end{array}$ & $\begin{array}{c}\text { Time } \\
(\text { days })\end{array}$ & $\begin{array}{c}\text { Moisture } \\
\text { Content * } \\
(\% W M E)\end{array}$ & $\begin{array}{c}\text { Time } \\
(\text { days })\end{array}$ & $\begin{array}{c}\text { Moisture } \\
\text { Content } \\
(\% W M E)\end{array}$ \\
\hline 0 & NA & 0 & NA & 0 & $9.1-9.1$ \\
\hline 75 & $18.7-11.2$ & 92 & $100-<6$ & 15 & $46-14.4$ \\
\hline 117 & $20.3-16.4$ & 127 & $100-<6$ & 36 & $67-12.2$ \\
\hline 146 & $22.1-15.2$ & 212 & $100-<6$ & 50 & $68-12.7$ \\
\hline 182 & $26.5-17$ & 255 & $100-<6$ & 106 & $100-12.4$ \\
\hline 341 & $17.7-11.8$ & 398 & $100-<6$ & 203 & $100-11.1$ \\
\hline 350 & $13-8.8$ & 432 & $100-<6$ & 316 & $44-10.1$ \\
\hline 391 & $23.6-13.3$ & 493 & $100-<6$ & & \\
\hline 411 & $21.2-14.5$ & & & & \\
\hline 440 & $31.3-16$ & & & & \\
\hline 473 & $29.2-12.5$ & & & & \\
\hline 516 & $26.3-13.8$ & & & & \\
\hline
\end{tabular}

* Moisture content (when measured) was typically measured at several elevations along the OD surface of the removable sections. The range reported reflects the measurements closest to the bottom of the lower section and closest to the top of the upper section. 
Table 2. Summary of test LE1 weight change for different heat and caplug configurations

\begin{tabular}{|l|l|l|l|l|}
\hline $\begin{array}{l}\text { Configuration } \\
\text { (external environment, internal heat source, } \\
\text { caplug configuration) }\end{array}$ & $\begin{array}{l}\text { Init. Wt } \\
(\mathrm{kg})\end{array}$ & $\begin{array}{l}\text { Final } \\
\text { Wt (kg) }\end{array}$ & $\begin{array}{l}\text { Duration * } \\
(\text { days })\end{array}$ & $\begin{array}{l}\text { Rate of Wt } \\
\text { Change ** } \\
\text { (\%/day) }\end{array}$ \\
\hline 142F 80\%RH external, 10 watts, caplugs & 184.12 & 183.89 & 33 & $-3.78 \mathrm{E}-3$ \\
\hline 142F 80\%RH external, 10 watts, no caplugs & 183.89 & 183.55 & 42 & -4.40 E-3 \\
\hline 142F 80\%RH external, 12 watts, no caplugs & 183.54 & 182.17 & 301 & -2.47 E-3 \\
\hline 142F 80\%RH external, 12 watts, caplugs & 182.17 & 181.92 & 125 & -1.09 E-3 \\
\hline
\end{tabular}

* some durations are shorter than cited in the text to match the intervals between weighings within each condition.

** \% change in weight is calculated relative to the initial package weight of $184.12 \mathrm{~kg}$.

Table 3. Dimensional measurements of LE2 shield to investigate the potential for lead creep.

\begin{tabular}{|l|l|l|l|}
\hline $\begin{array}{l}\text { Time of } \\
\text { Measurement }\end{array}$ & $\begin{array}{l}\text { Avg Radial Thickness at } \\
\text { Bottom of Shield (inch) }\end{array}$ & $\begin{array}{l}\text { Avg Radial Thickness } \\
\text { at Top of Shield (inch) }\end{array}$ & $\begin{array}{l}\text { Difference } \\
\text { (Bottom - Top) (inch) }\end{array}$ \\
\hline Baseline & 0.540 & 0.542 & -0.002 \\
\hline After 36 wks & 0.574 & 0.550 & +0.024 \\
\hline After 81 wks & 0.572 & 0.546 & +0.026 \\
\hline
\end{tabular}

Table 4. Compression set data for LE2 O-rings

\begin{tabular}{|l|l|l|l|l|}
\hline & \multicolumn{4}{|c|}{ O-Ring Compression Set } \\
\hline $\begin{array}{l}\text { Interval between opening vessel } \\
\text { and O-Ring measurements }\end{array}$ & $\begin{array}{l}\text { PCV Inner } \\
\text { O-Ring }\end{array}$ & $\begin{array}{l}\text { PCV Outer } \\
\text { O-Ring }\end{array}$ & $\begin{array}{l}\text { SCV Inner } \\
\text { O-Ring }\end{array}$ & $\begin{array}{l}\text { SCV Outer } \\
\text { O-Ring }\end{array}$ \\
\hline 5 minutes & $58 \%$ & $58 \%$ & $67 \%$ & $60 \%$ \\
\hline 24 minutes & $57 \%$ & $54 \%$ & $54 \%$ & $57 \%$ \\
\hline 9 days & $36 \%$ & $*$ & $41 \%$ & $30 \%$ \\
\hline 30 days & $33 \%$ & $40 \% *$ & $45 \%$ & $26 \%$ \\
\hline
\end{tabular}

* This O-ring twisted upon removal. Measurements taken at 9 and 30 days were not consistently in the as-installed radial direction. The value reported at 30 days is based on re-measurement performed at 65 days.

Table 5. LE2 data used to estimate changes in fiberboard radial thermal conductivity

\begin{tabular}{|l|l|l|l|l|l|}
\hline $\begin{array}{l}\text { Time at } \\
\text { Temp. } \\
(\text { days })\end{array}$ & $\begin{array}{l}\text { Avg } \\
\text { Fiberboard ID } \\
\text { Temperature } \\
\left({ }^{\circ} \mathrm{F}\right)\end{array}$ & $\begin{array}{l}\text { Avg Fiberboard } \\
\text { Radial Temp. } \\
\text { Gradient, } \Delta \mathrm{T} \\
\left({ }^{\circ} \mathrm{F}\right)\end{array}$ & $\begin{array}{l}\text { Fiberboard } \\
\text { Radial } \\
\text { Thickness, } \mathrm{t} \\
(\mathrm{inch})\end{array}$ & $\begin{array}{l}\Delta \mathrm{T} / \mathrm{t} \\
\left({ }^{\circ} \mathrm{F} / \mathrm{inch}\right)\end{array}$ & $\begin{array}{l}\text { Normalized } \\
\text { Thermal } \\
\text { Conductivity, } \\
4.475 /(\Delta \mathrm{T} / \mathrm{t})\end{array}$ \\
\hline 18 & 247 & 21.58 & 4.822 & 4.475 & 1.000 \\
\hline 64 & 242 & 23.27 & 4.819 & 4.829 & 0.927 \\
\hline 188 & 245 & 24.53 & 4.813 & 5.097 & 0.878 \\
\hline 321 & 246 & 24.16 & 4.789 & 5.045 & 0.887 \\
\hline 348 & 241 & 24.65 & 4.784 & 5.153 & 0.869 \\
\hline 450 & 241 & 26.09 & 4.768 & 5.472 & 0.818 \\
\hline
\end{tabular}




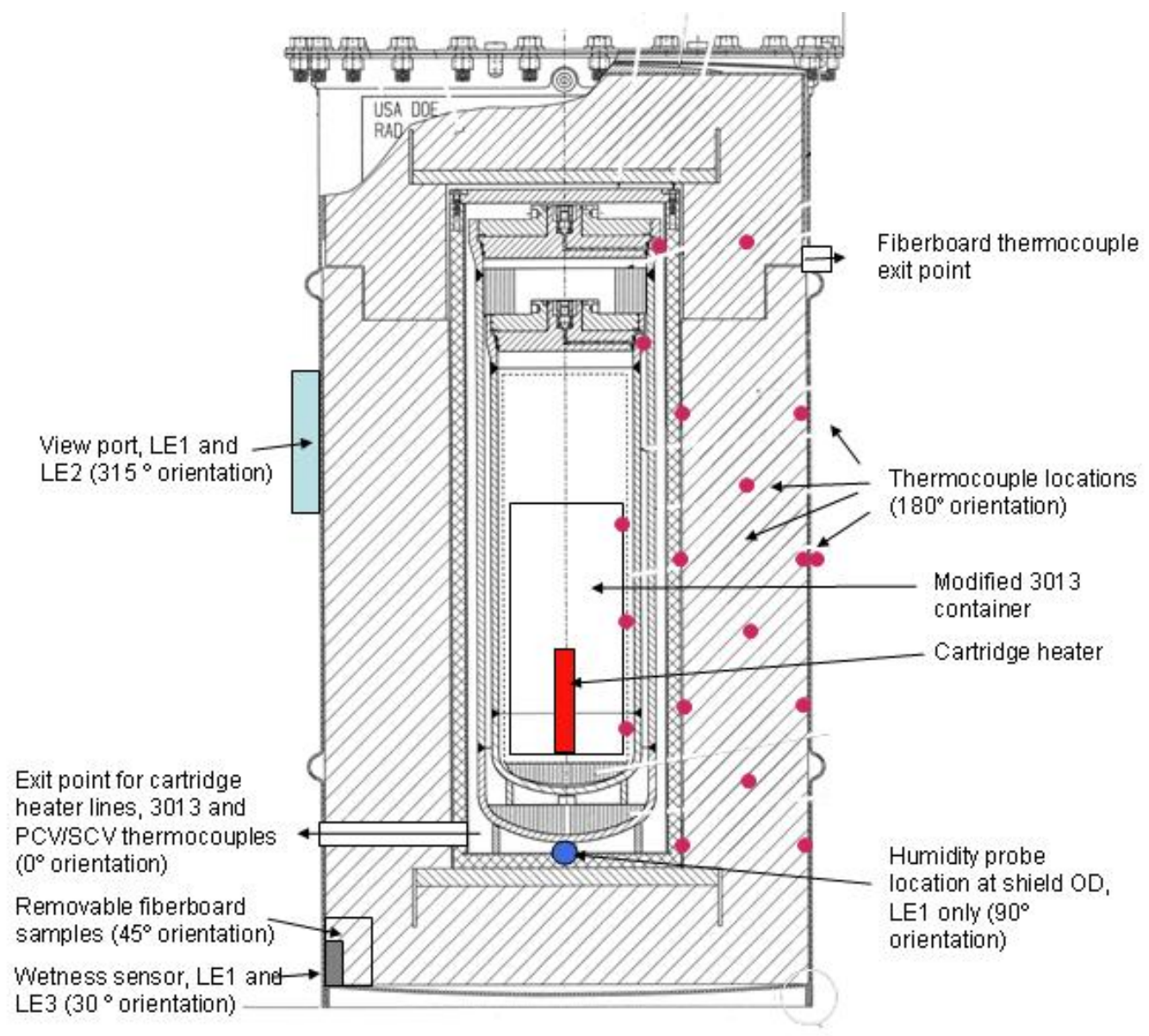

Figure 1. Cross section of 9975 package, showing added instrumentation and examination features. 


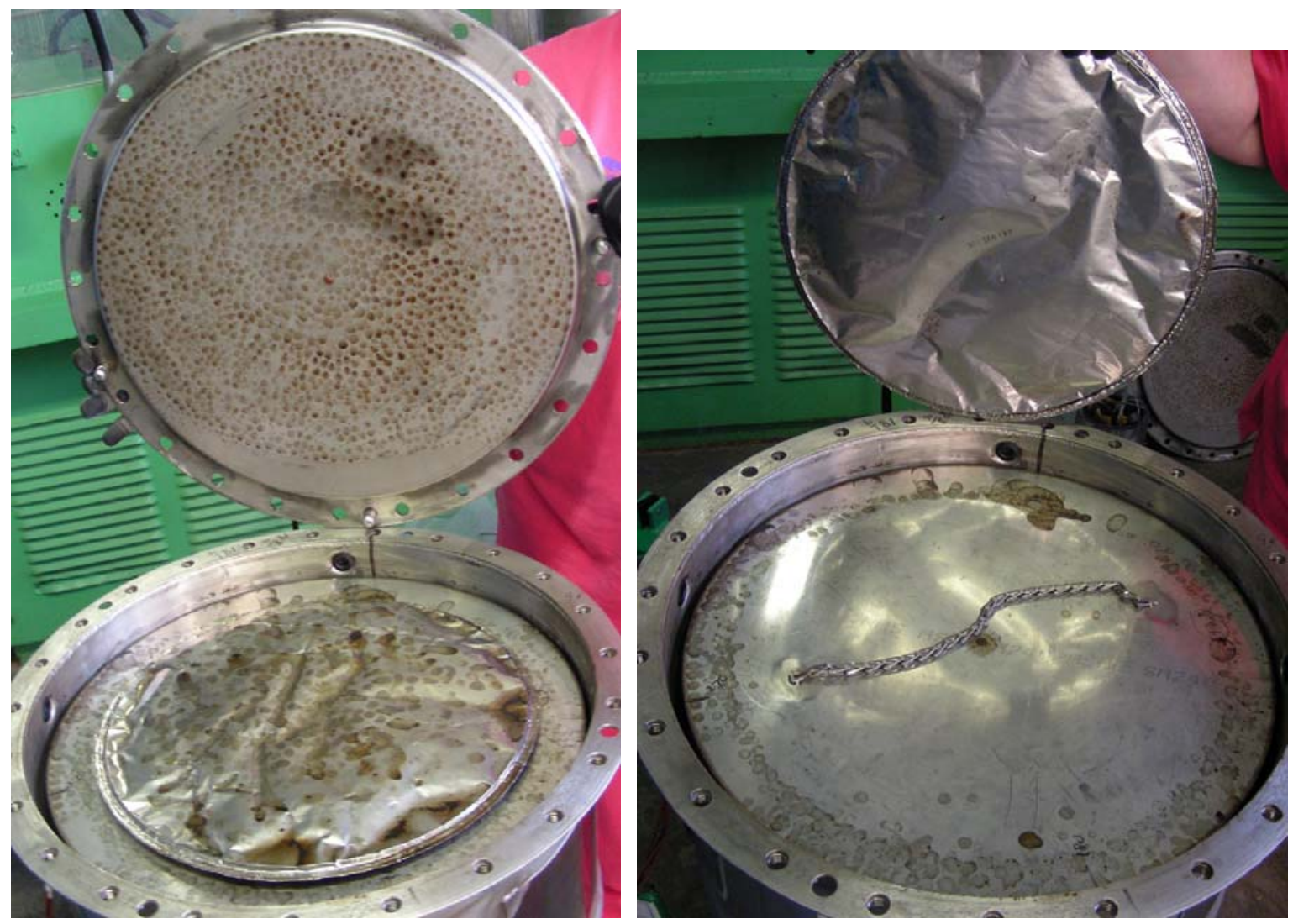

Figure 2. Stain on LE2 lid and other upper components from initial condensation activity.

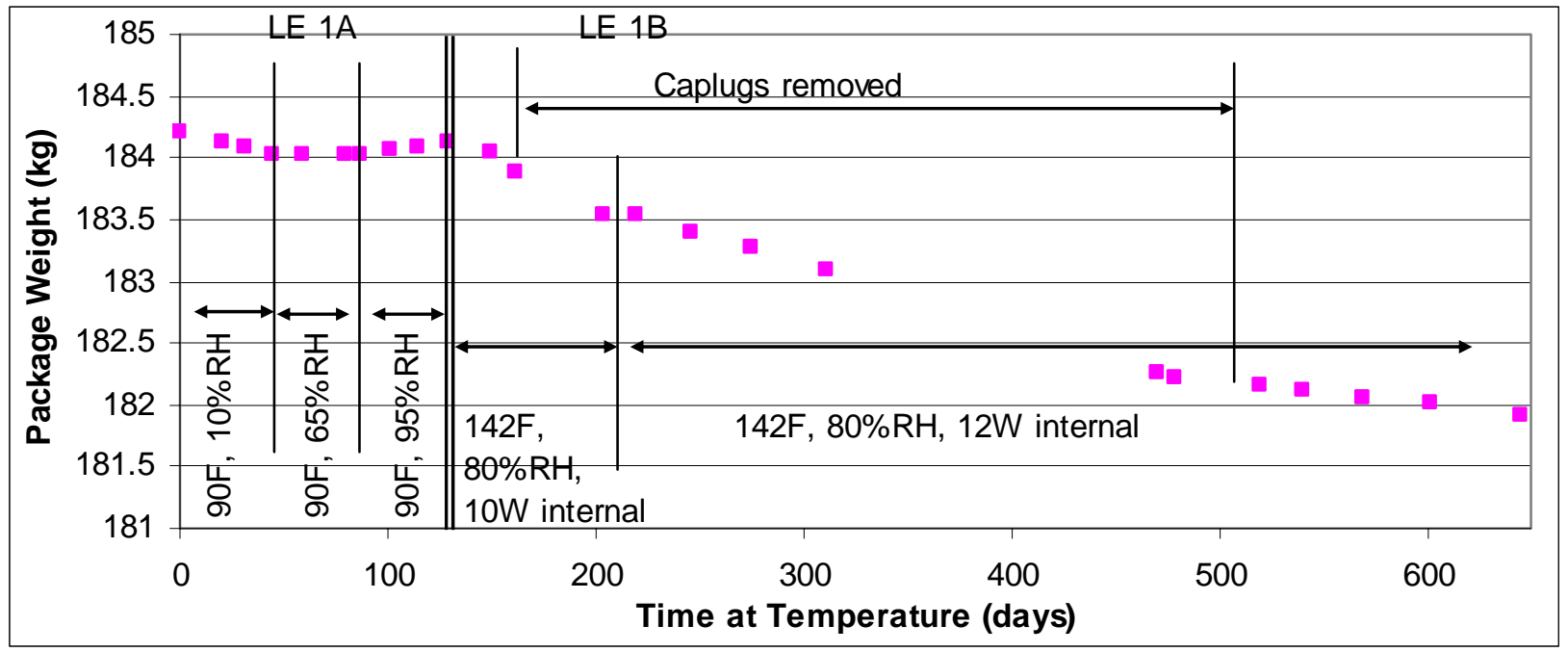

Figure 3. Package weight of LE1 over time. 


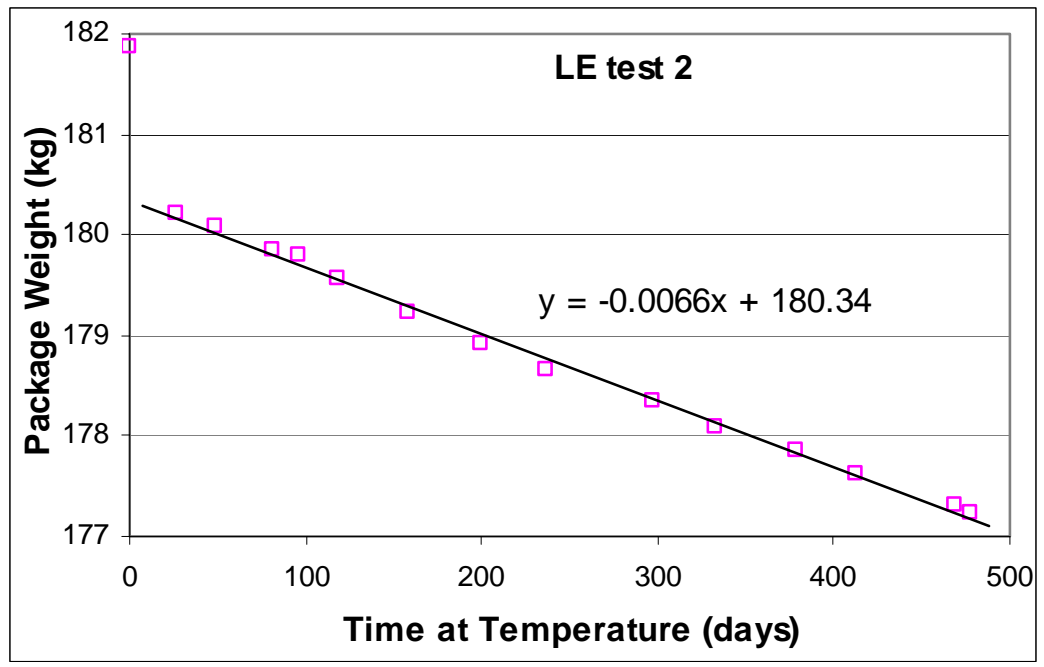

Figure 4. Package weight of LE2 over time. The variation following the initial drop is approximated well by the linear trendline. The magnitude of the initial drop represents moisture loss. The subsequent decrease in weight represents a combination of additional moisture loss and fiberboard pyrolysis.

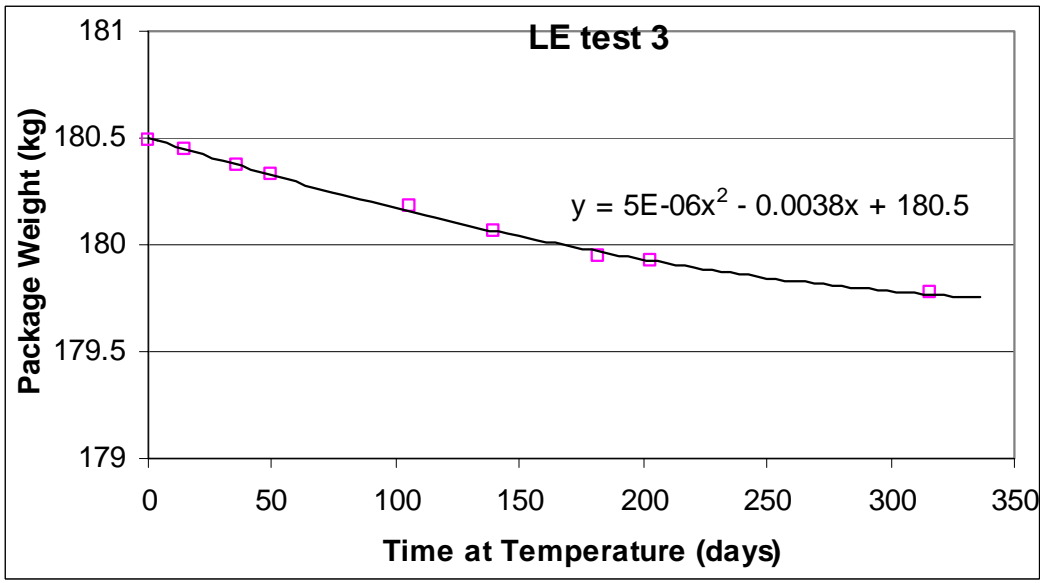

Figure 5. Package weight of LE3 over time. The data are well represented by a quadratic trendline. 


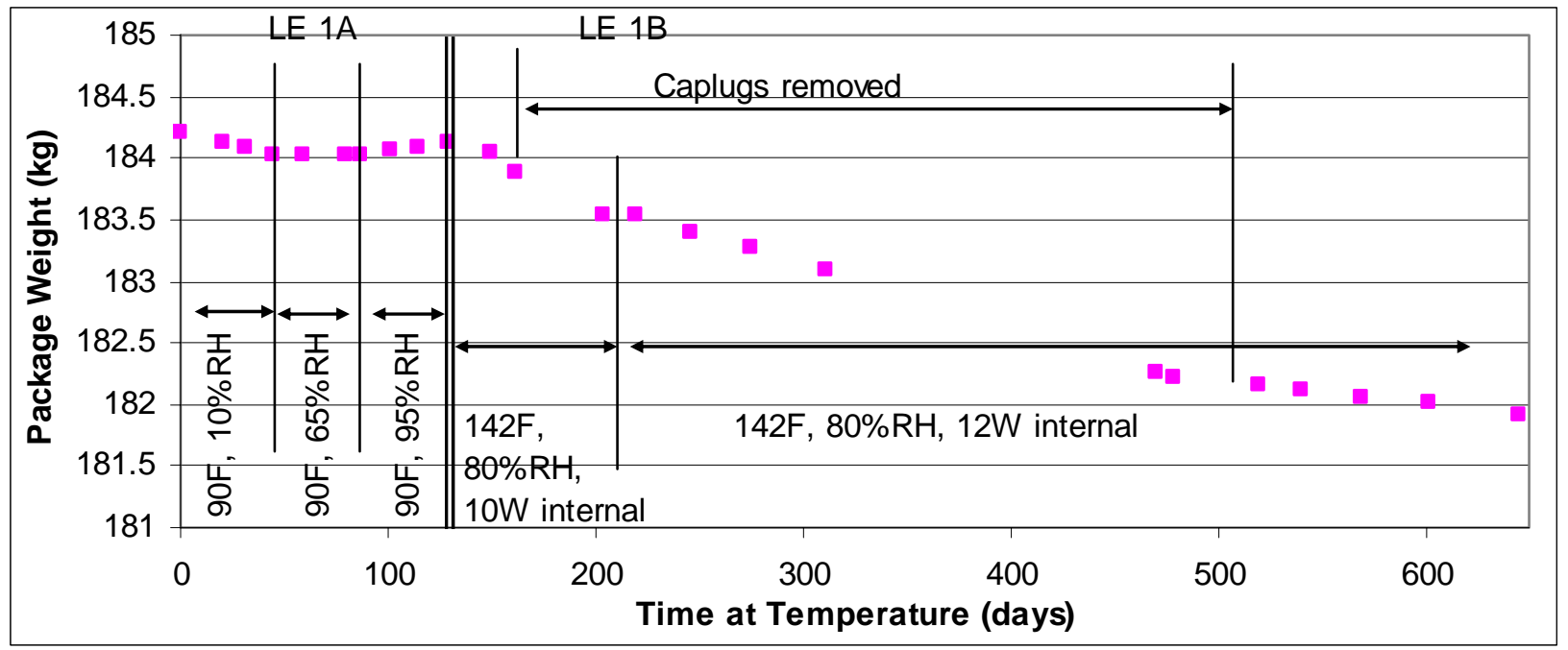

Figure 6. Relative humidity near the fiberboard ID surface for LE 1 . The major short-term fluctuations in humidity correspond to inspections when the package was opened.

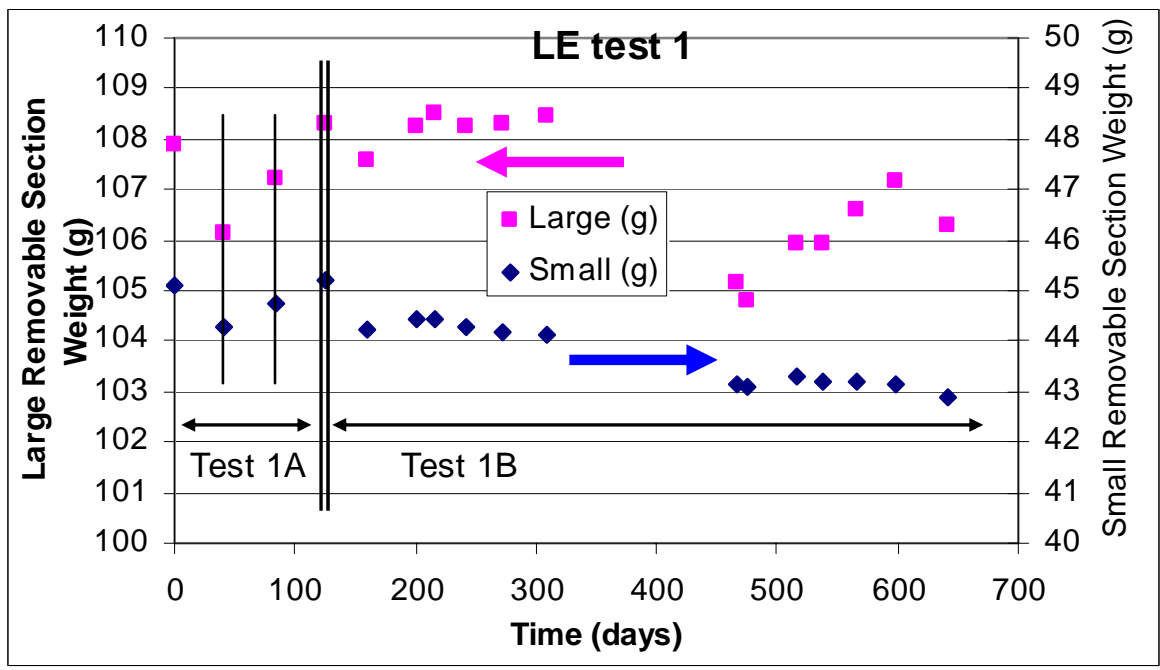

Figure 7. Weight of removable fiberboard sections from life extension test 1. 


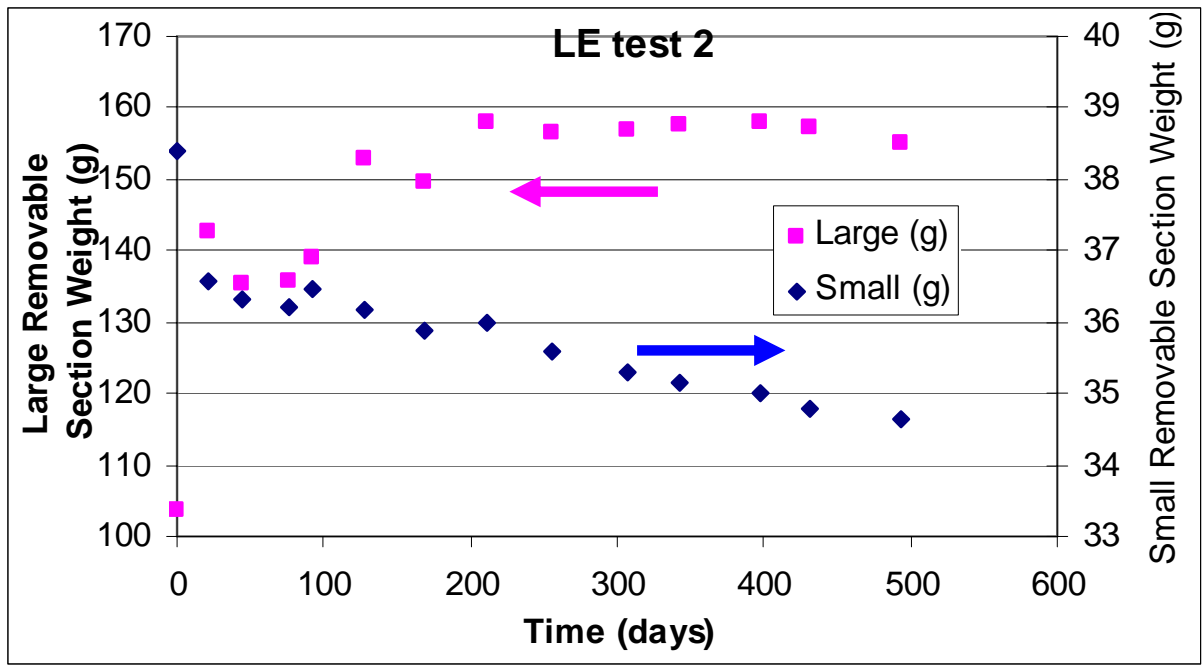

Figure 8. Weight of removable fiberboard sections from life extension test 2.

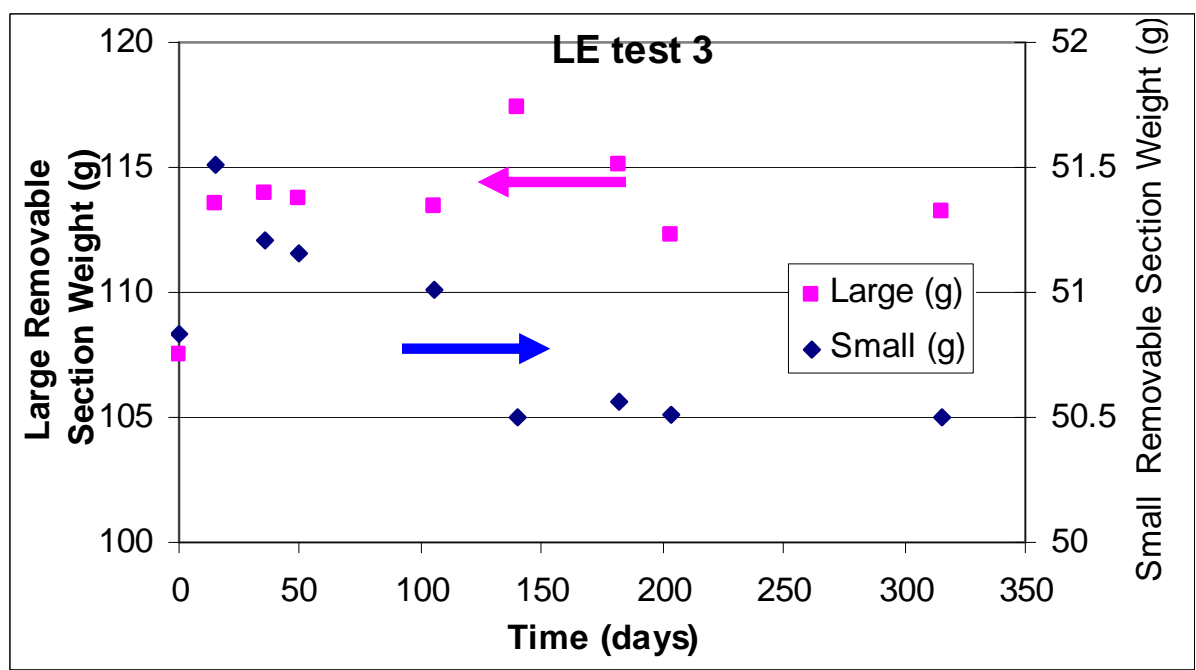

Figure 9. Weight of removable fiberboard sections from life extension test 3. 


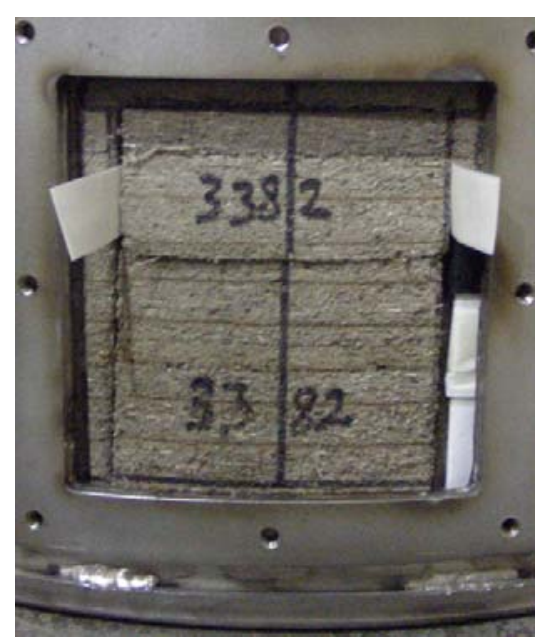

(a) baseline

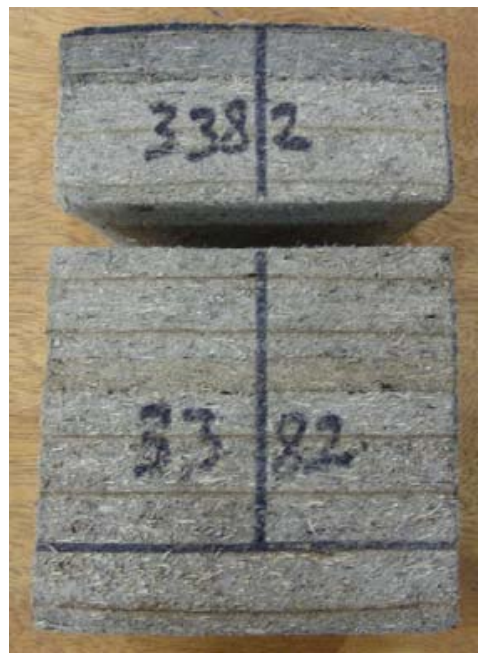

(b) after 6 wks $90^{\circ} \mathrm{F} 95 \% \mathrm{RH}(\mathrm{c})$ after $63 \mathrm{wks} 142^{\circ} \mathrm{F}, 30 \% \mathrm{RH}$

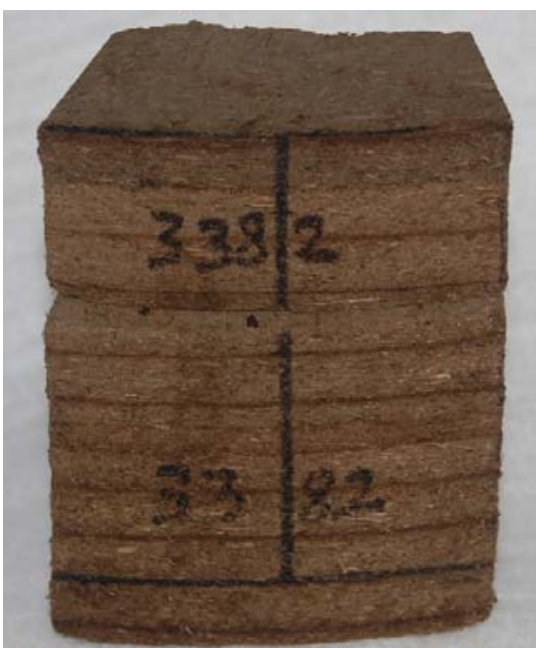
Figure 10. Sequence of photographs of small removable fiberboard sections from test LE1.

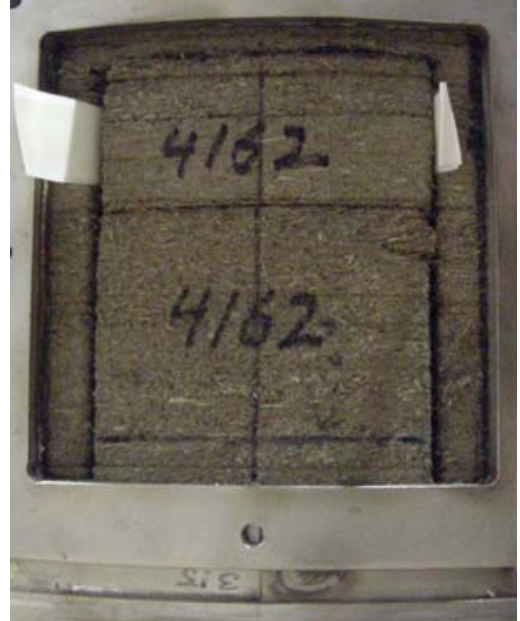

(a) baseline

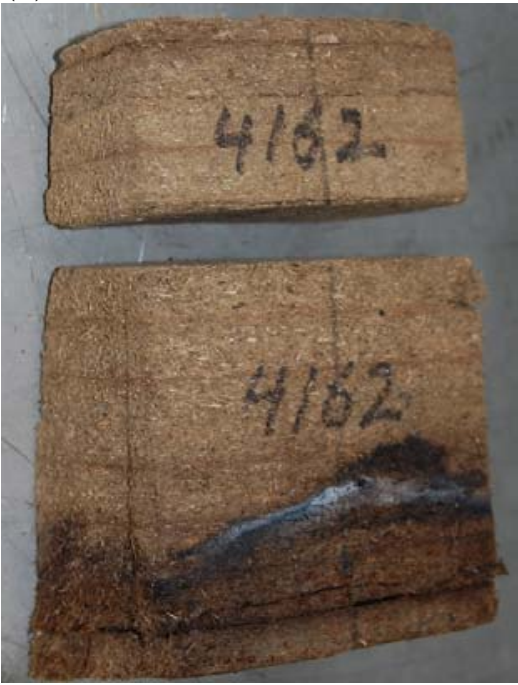

(d) $49 \mathrm{wk}$

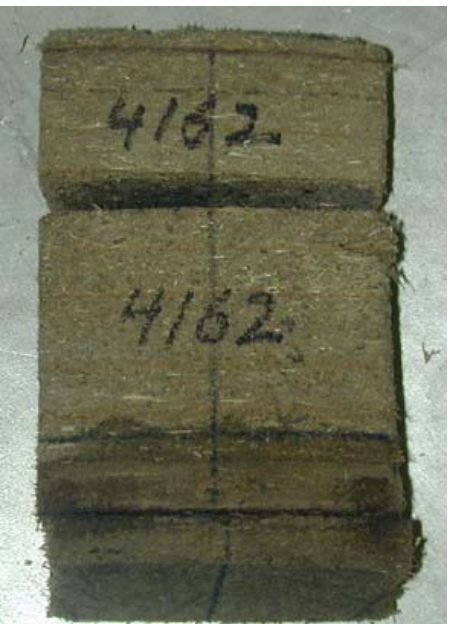

(b) $9 \mathrm{wk}$

(c) $19 \mathrm{wk}$ 


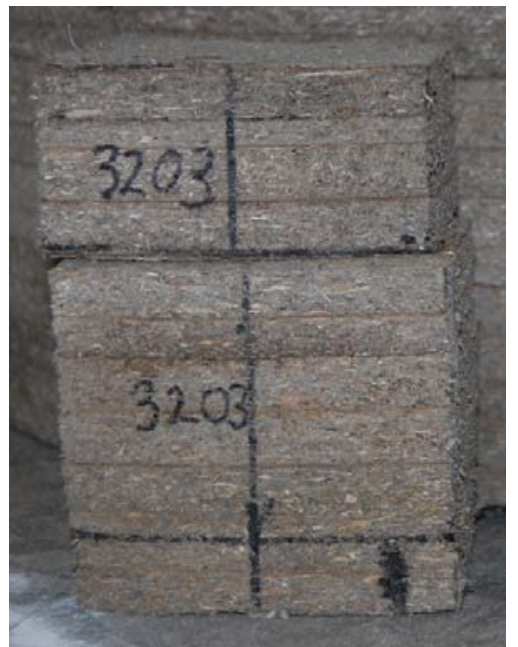

(a) baseline

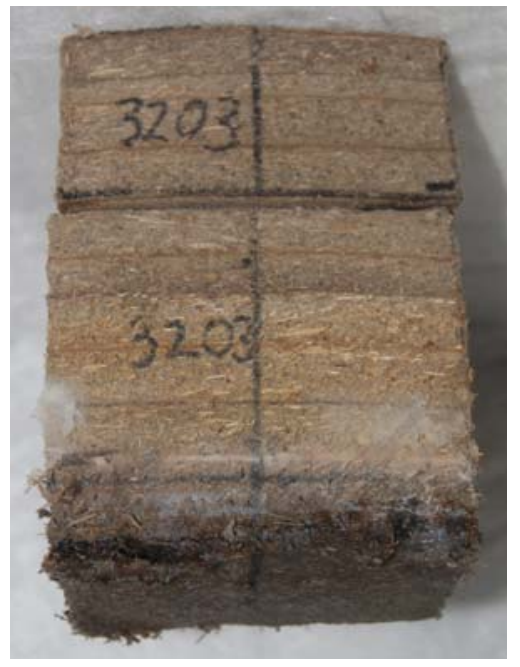

(d) $45 \mathrm{wk}$

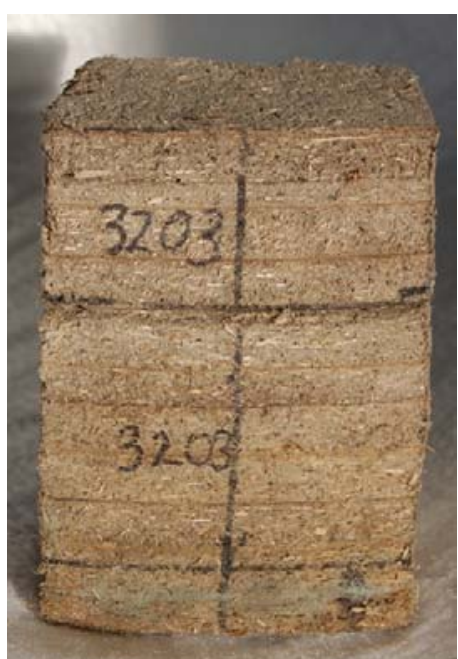

(b) $5 \mathrm{wk}$

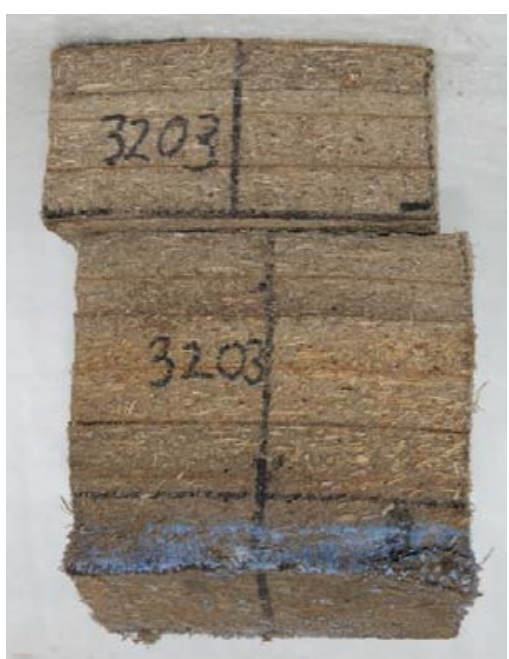

(c) $15 \mathrm{wk}$

Figure 12. Sequence of photographs of small removable fiberboard sections from test LE3. 


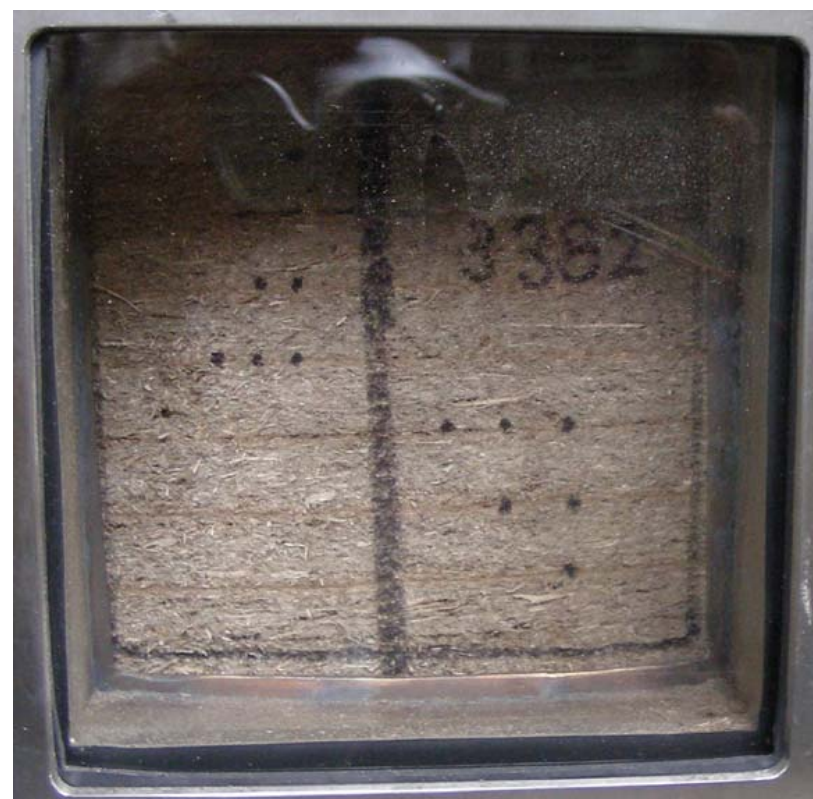

(a)

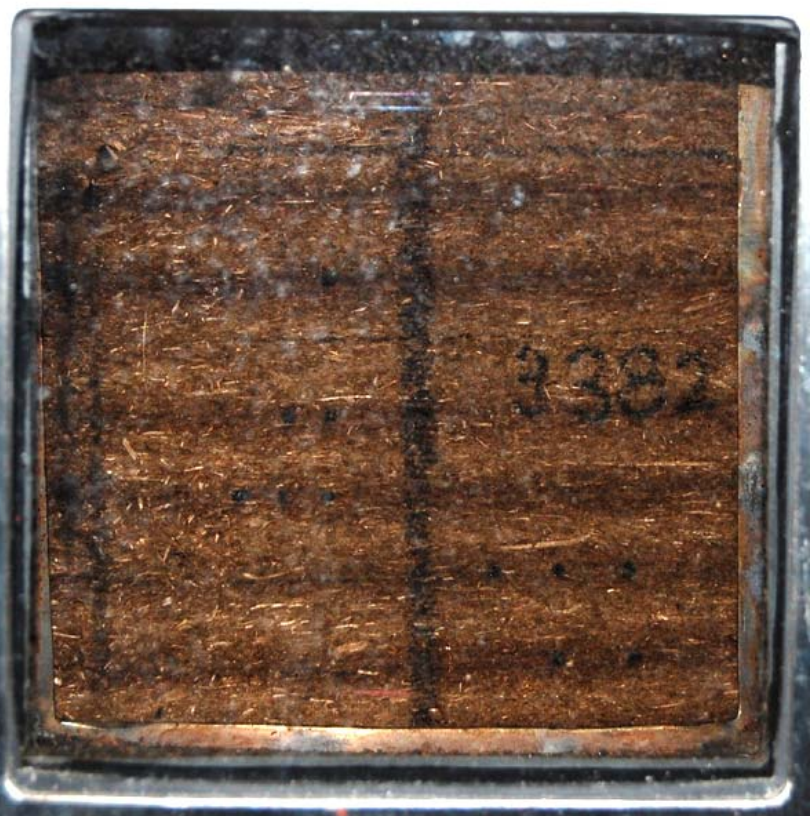

(b)

Figure 13. View of the side of test LE1 through the view port at time 0 (a) and after 53 weeks (b)

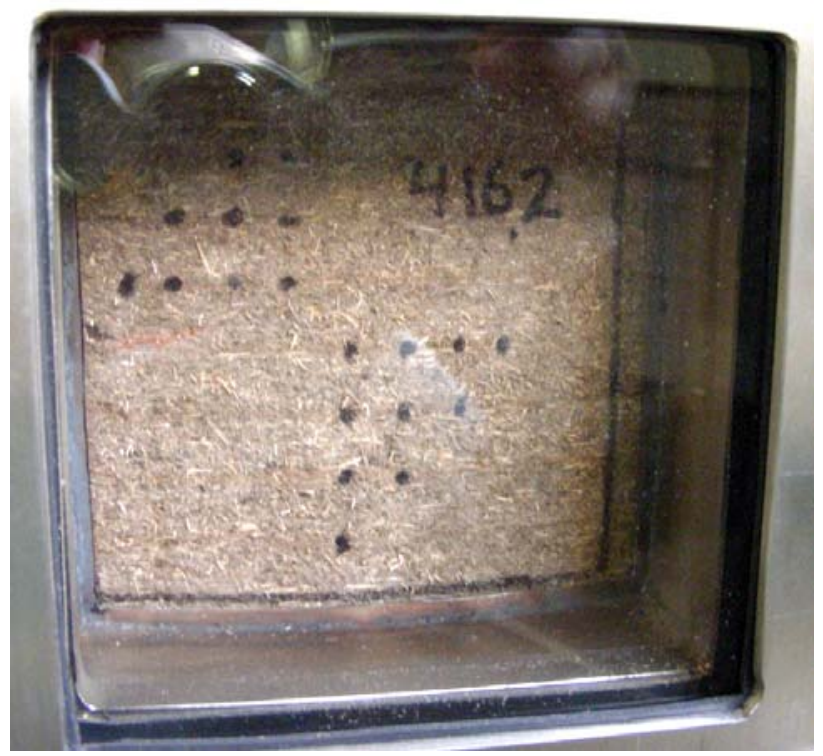

(a)

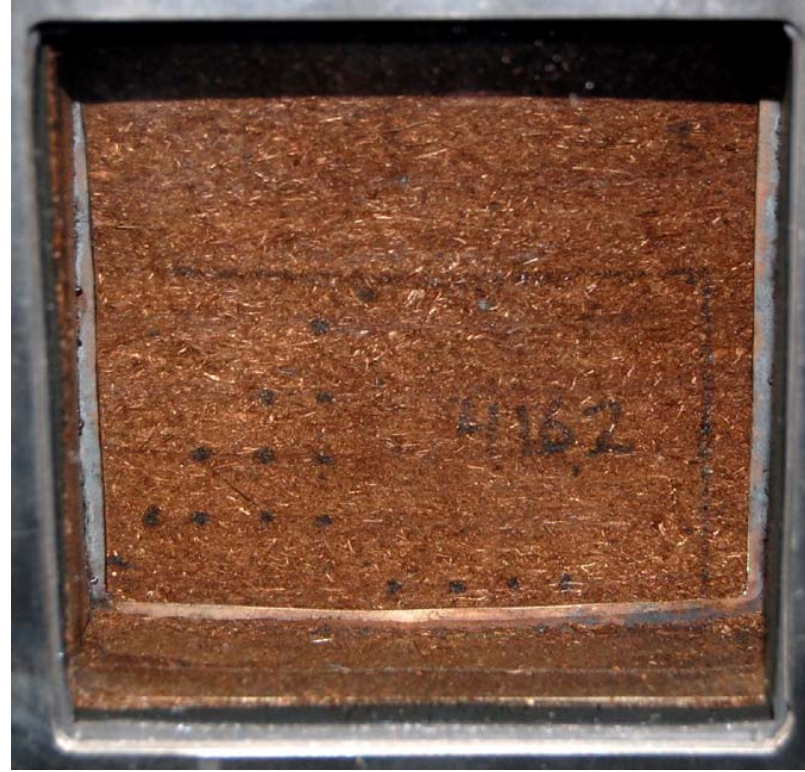

(b)

Figure 14. View of the side of test LE2 through the view port at time 0 (a) and after 81 weeks (b) 


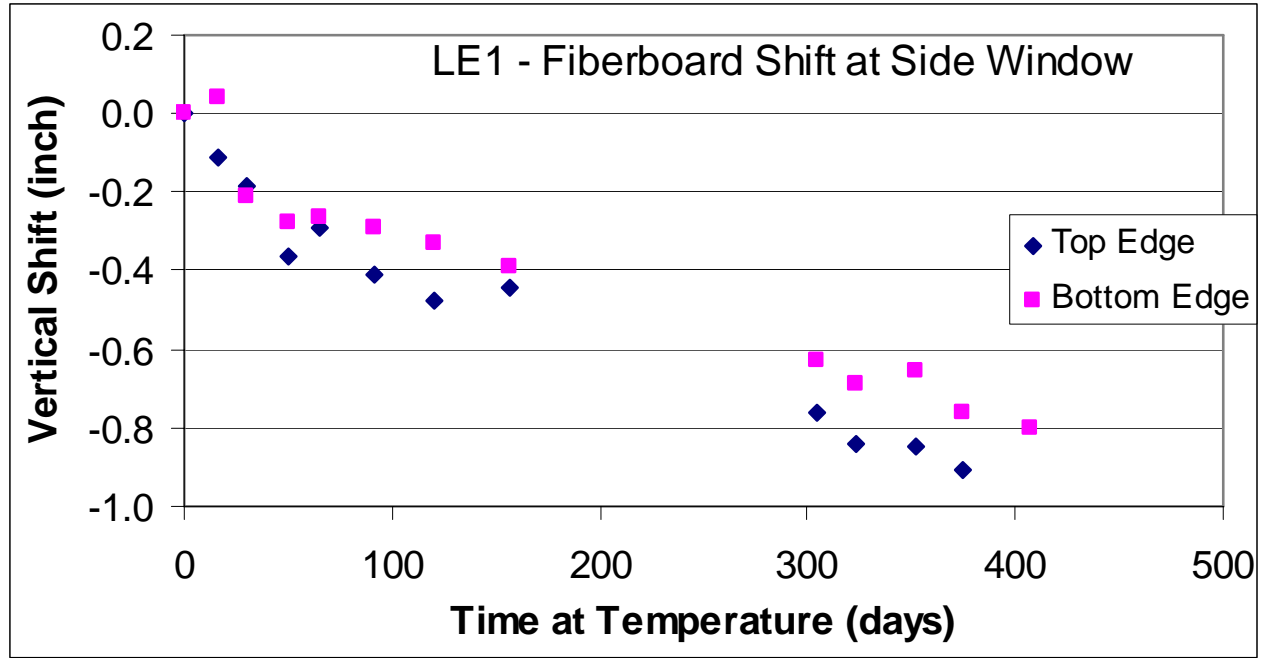

Figure 15. Vertical shift (downward) of fiberboard in LE1b, as viewed through the side view port.

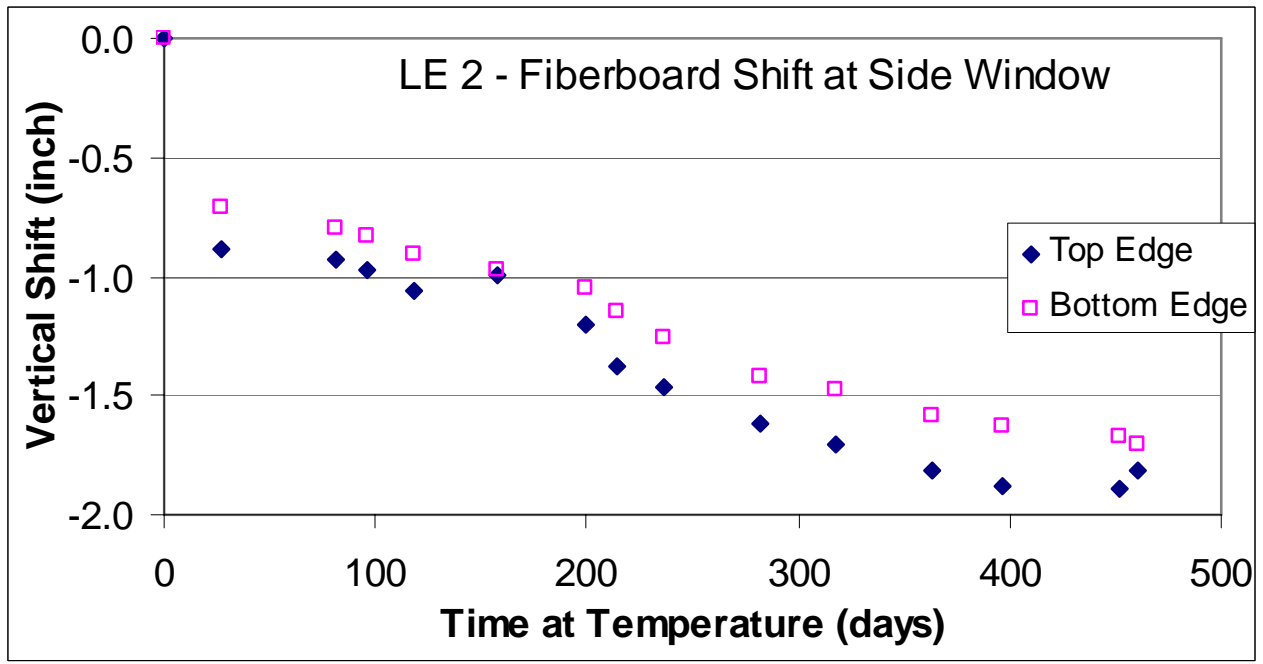

Figure 16. Vertical shift (downward) of fiberboard in LE2, as viewed through the side view port. 


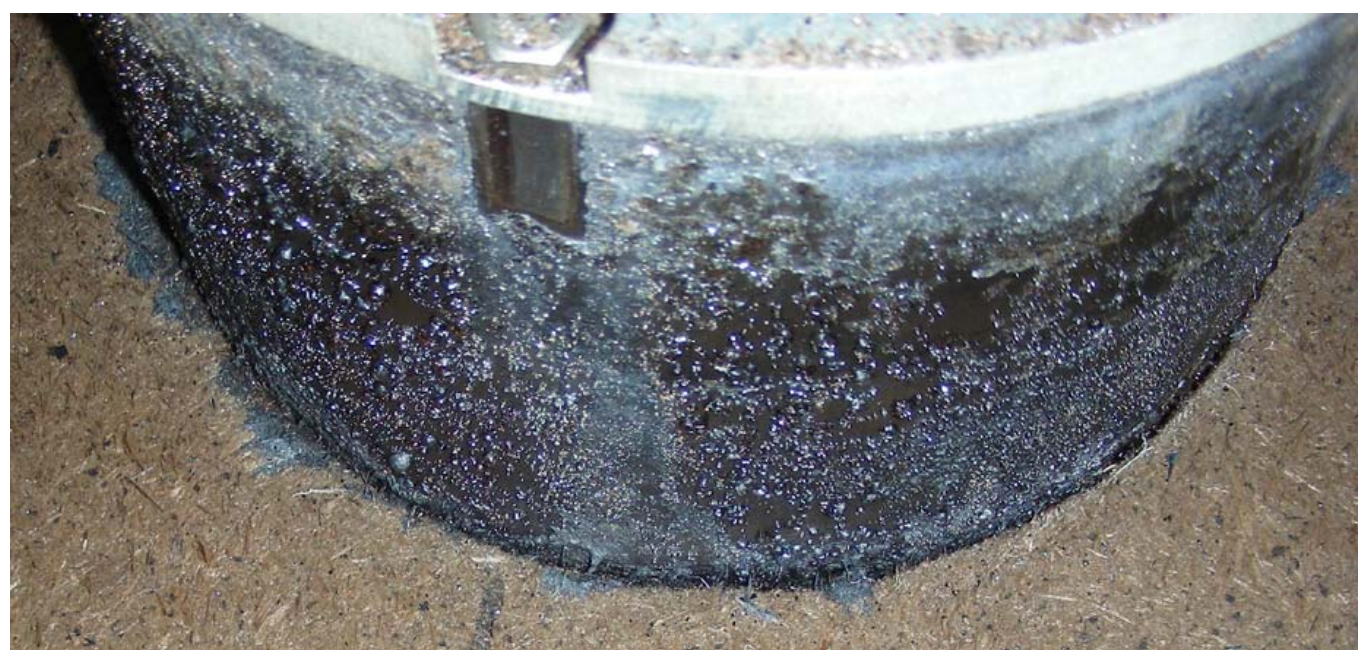

Figure 17. Corrosion product on the LE2 shield, after 19 weeks in test.

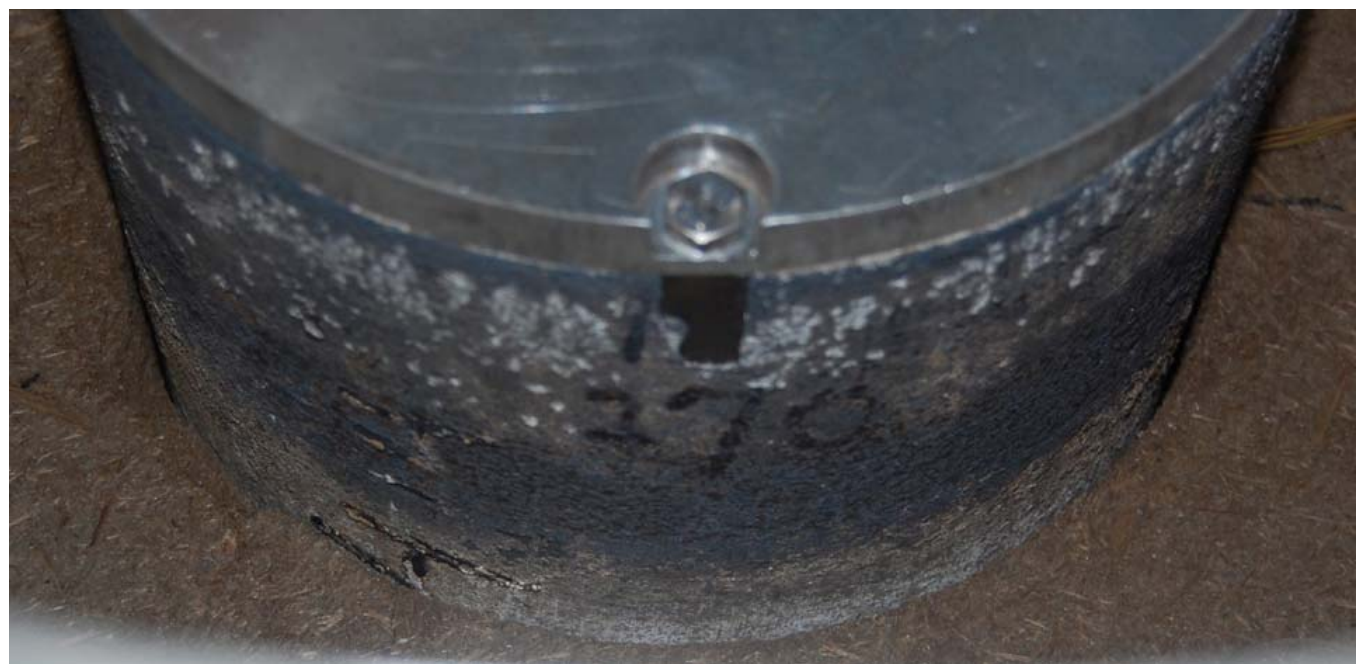

Figure 18. Corrosion product on the LE1 shield, after 63 weeks in test.

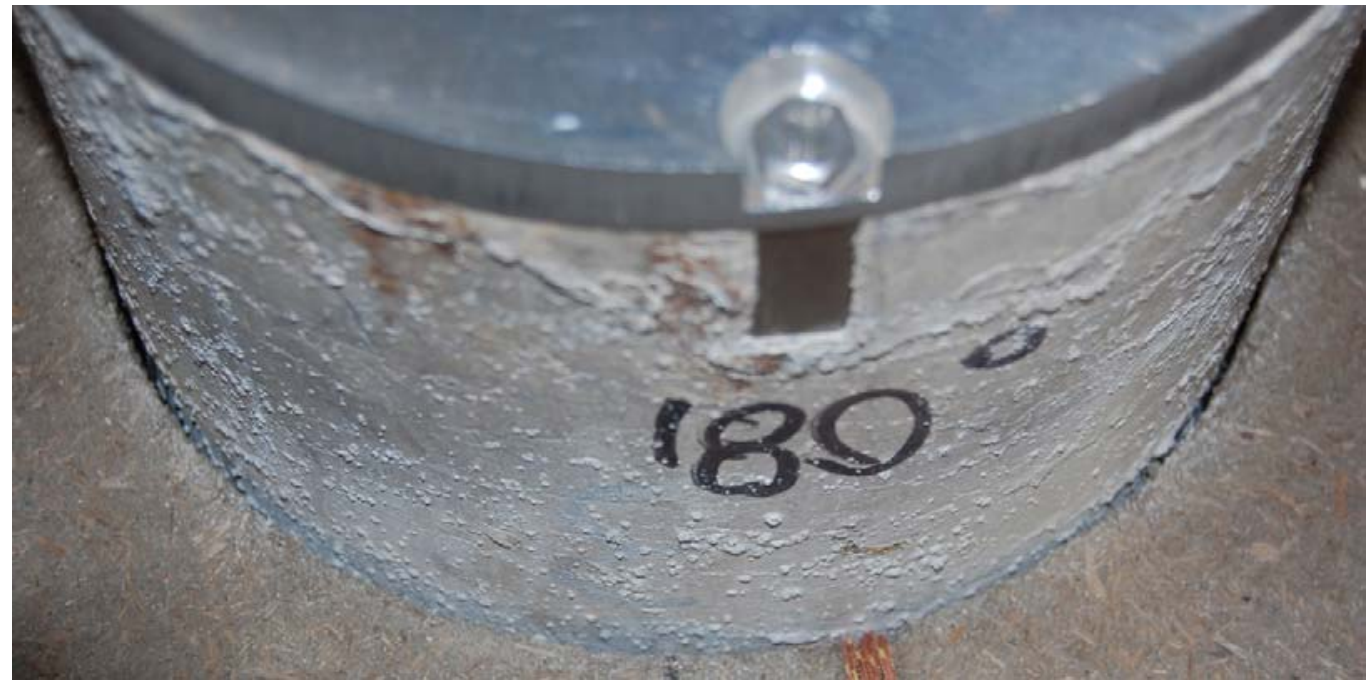

Figure 19. Corrosion product on the LE3 shield, after 45 weeks in test. 


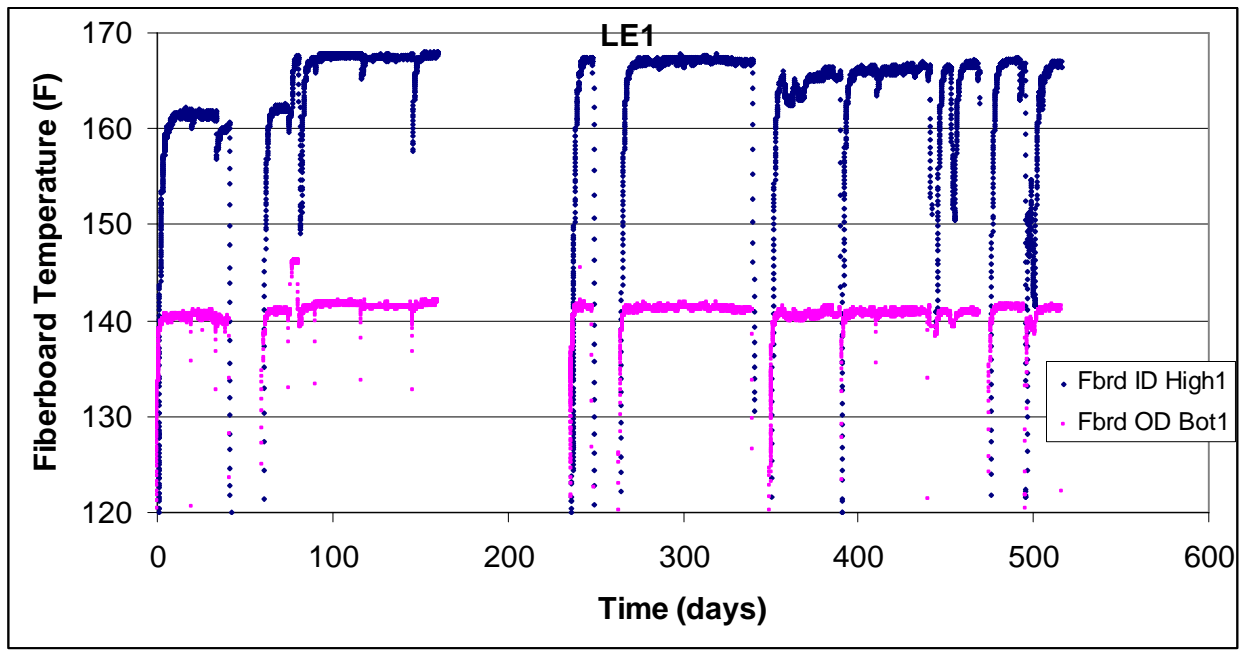

(a) LE1 phase b

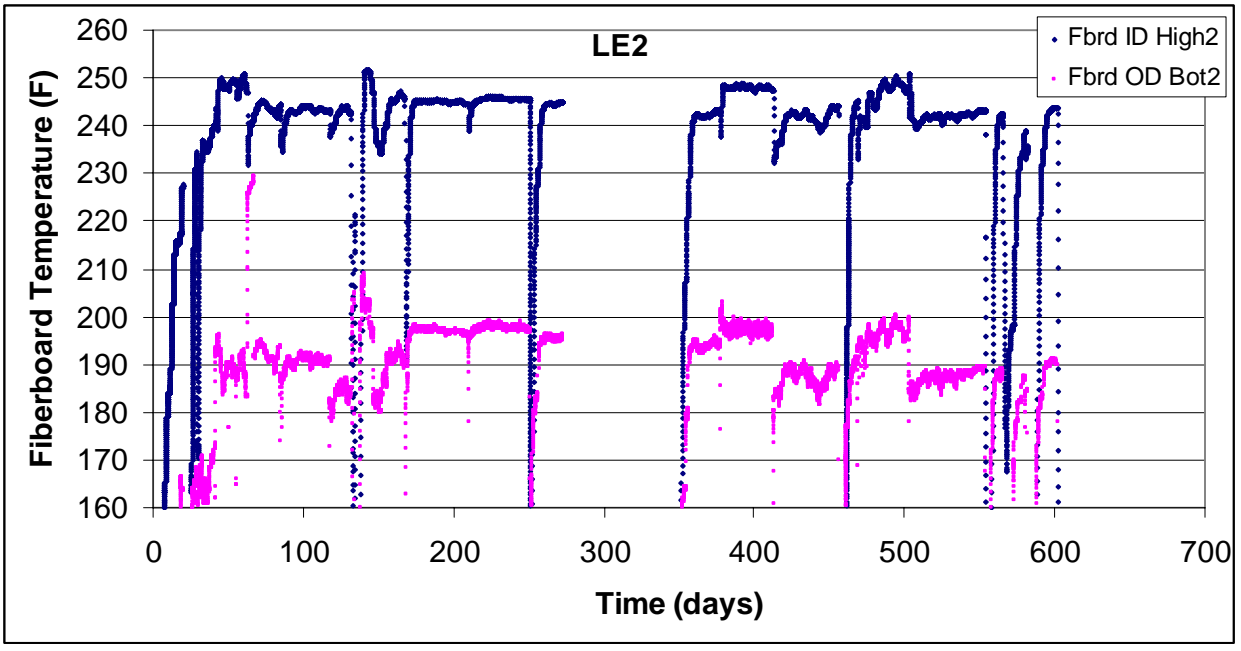

(b) LE2

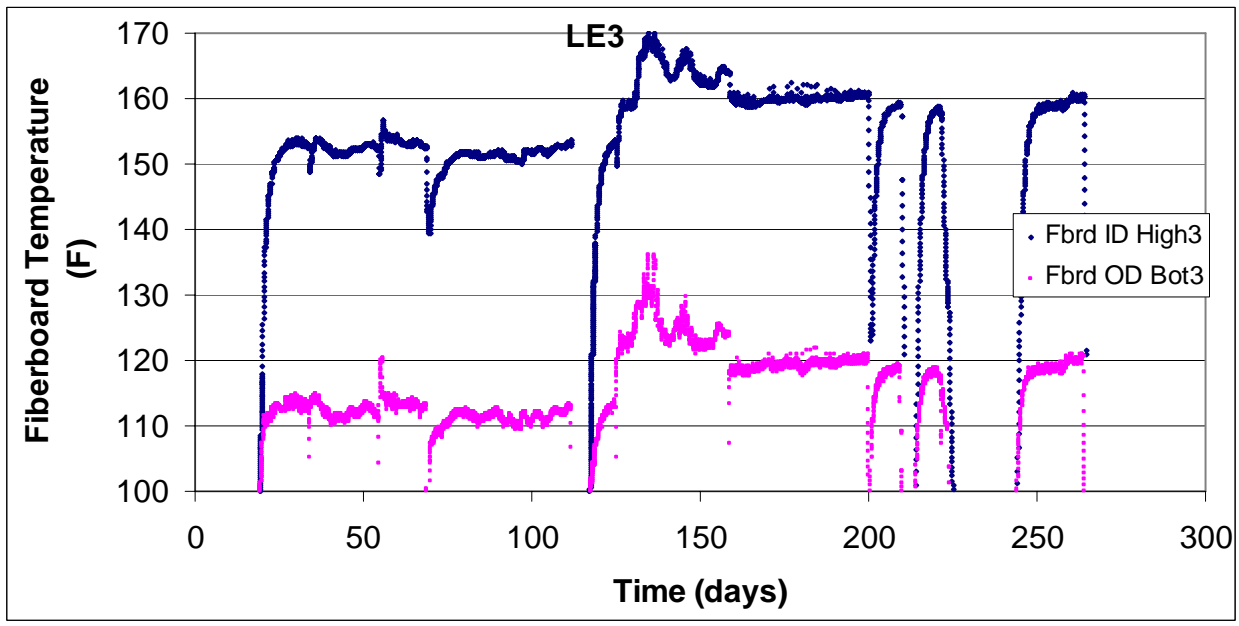

(c) LE3

Figure 20. Temperature variation for each package at the hottest (blue symbols) and coolest (pink symbols) instrumented fiberboard locations (highest fiberboard ID location and lowest fiberboard OD location - refer to Figure 1). 


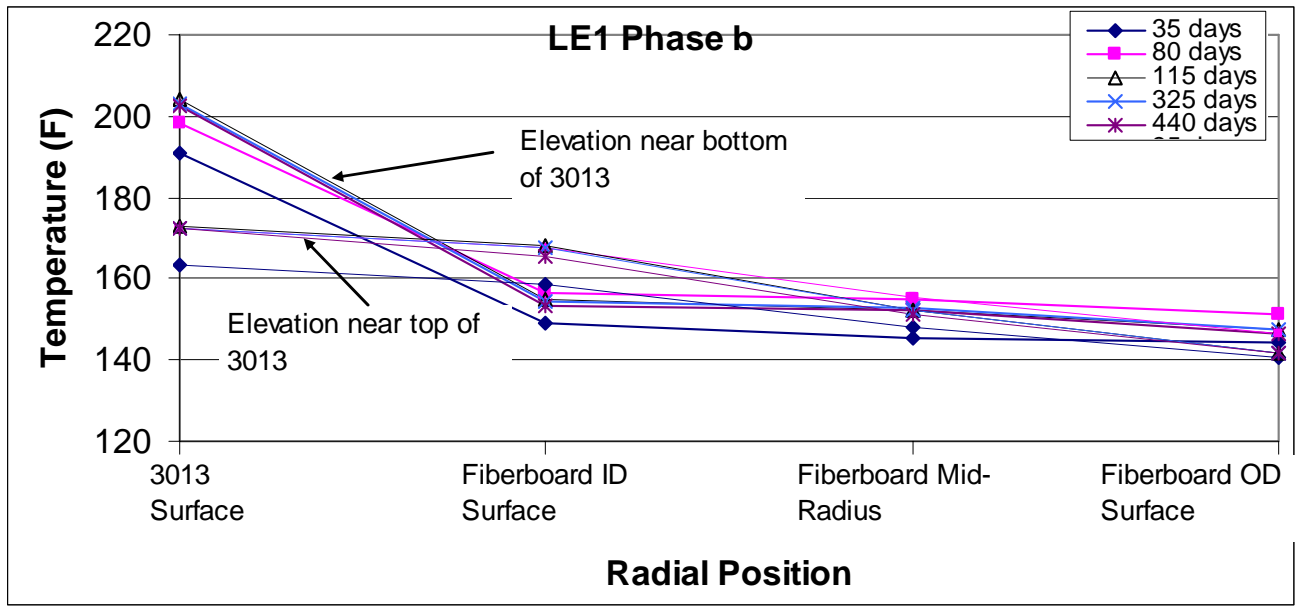

(a) LE1 phase b

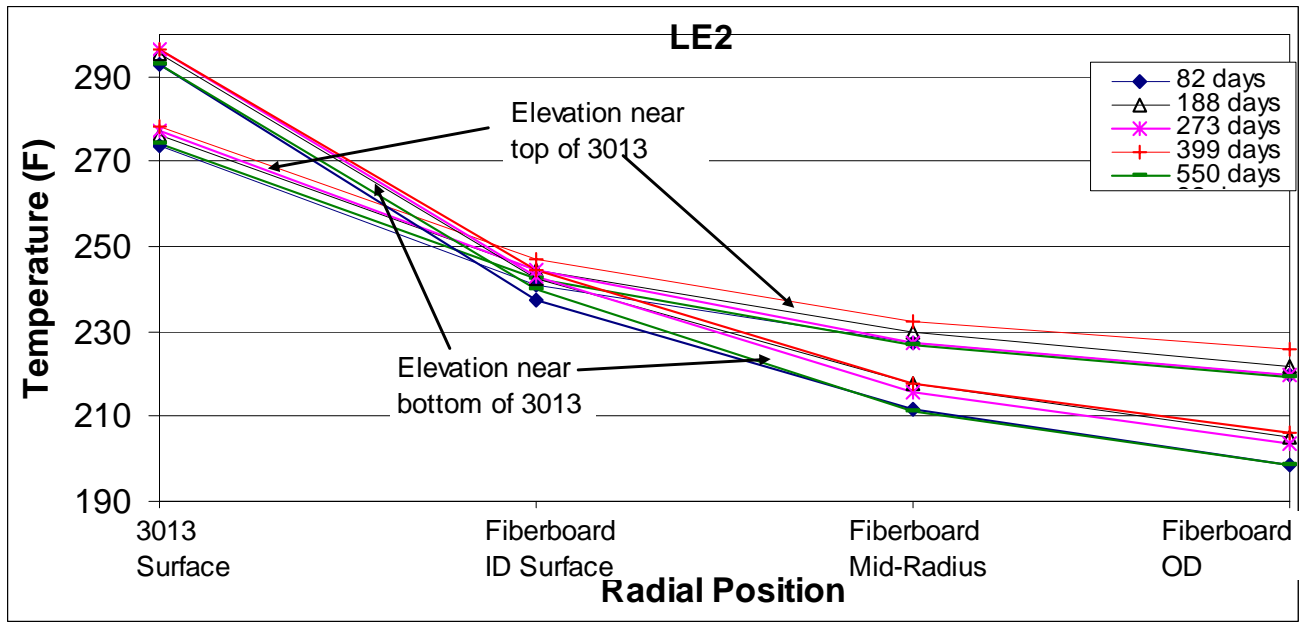

(b) LE2

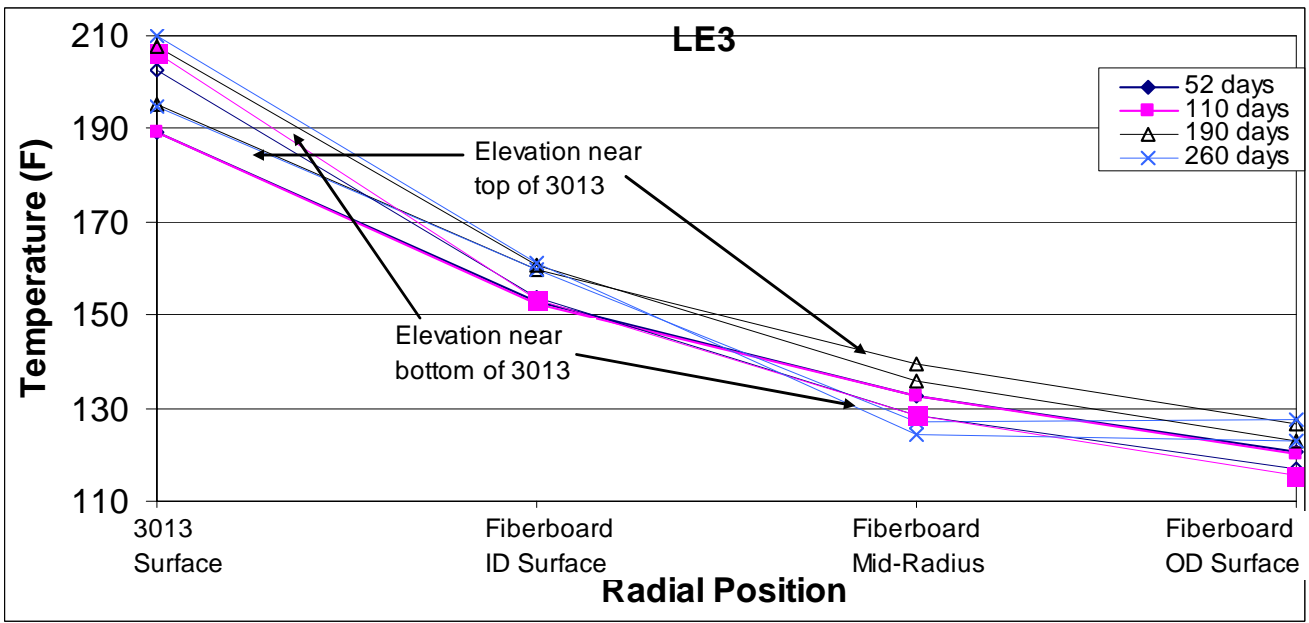

(c) LE3

Figure 21. Radial temperature profiles at several intervals of steady state temperature. 


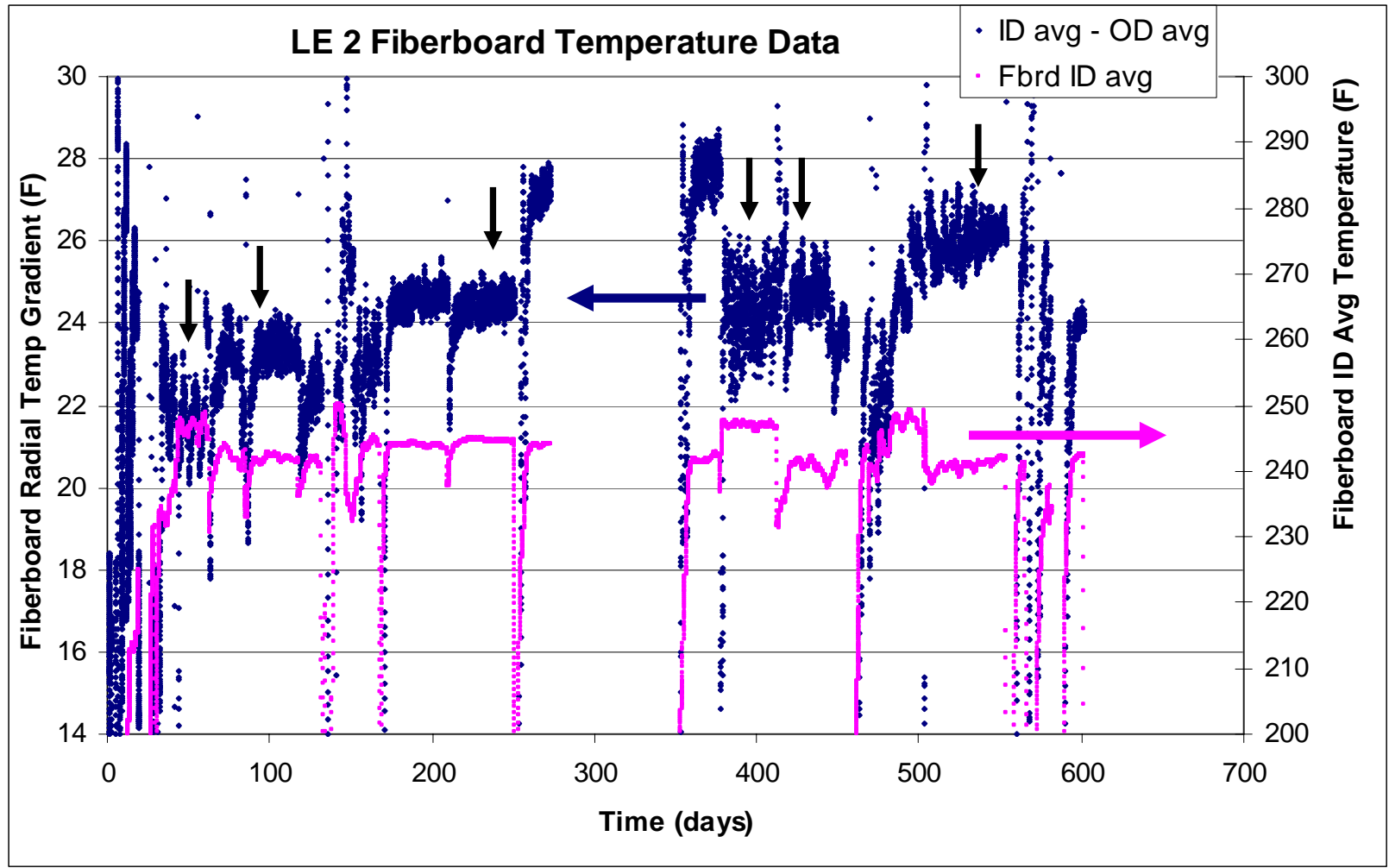

Figure 22. LE package 2 average radial temperature gradient (blue symbols) in the fiberboard based on the upper 3 fiberboard ID thermocouples and the upper 3 fiberboard OD thermocouples, and average fiberboard ID temperature (pink symbols). The vertical arrows indicate times during steady state operation for which the relative thermal conductivity of the fiberboard was estimated.

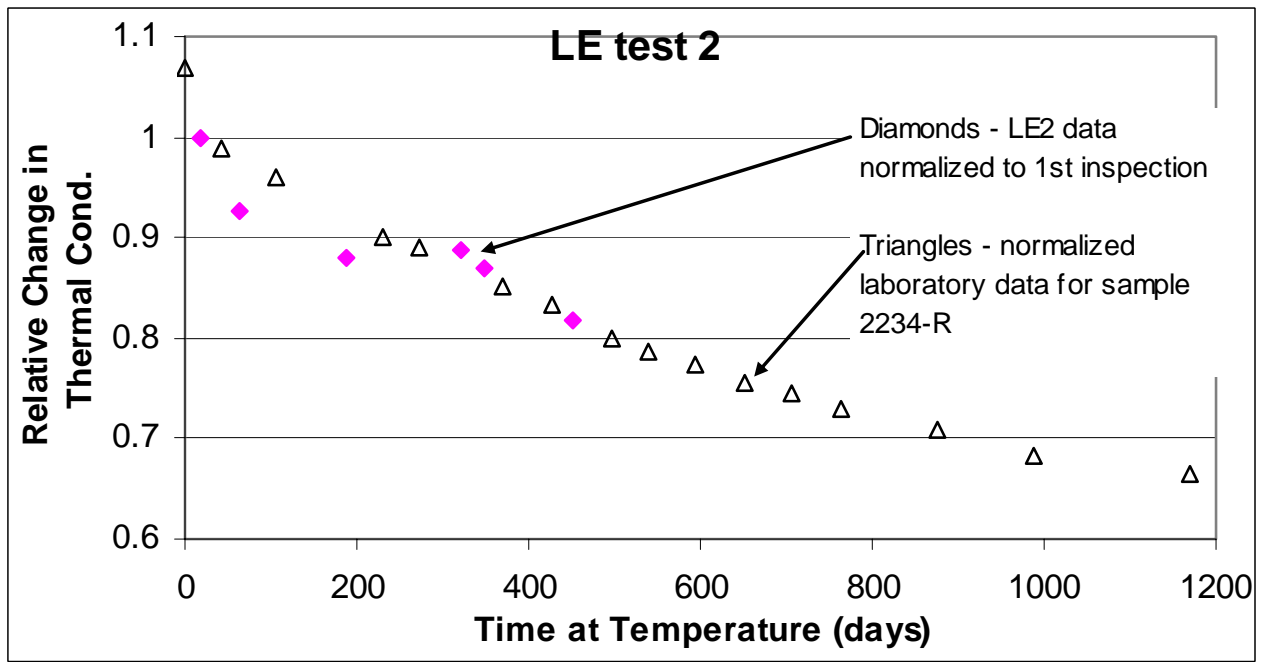

Figure 23. Relative change in thermal conductivity estimated from LE2 thermal gradient data, compared to comparable data from lab sample 2234-R. Data for the lab sample is shown for a mean test temperature of $185^{\circ} \mathrm{F}$ following conditioning at $250^{\circ} \mathrm{F}$. 


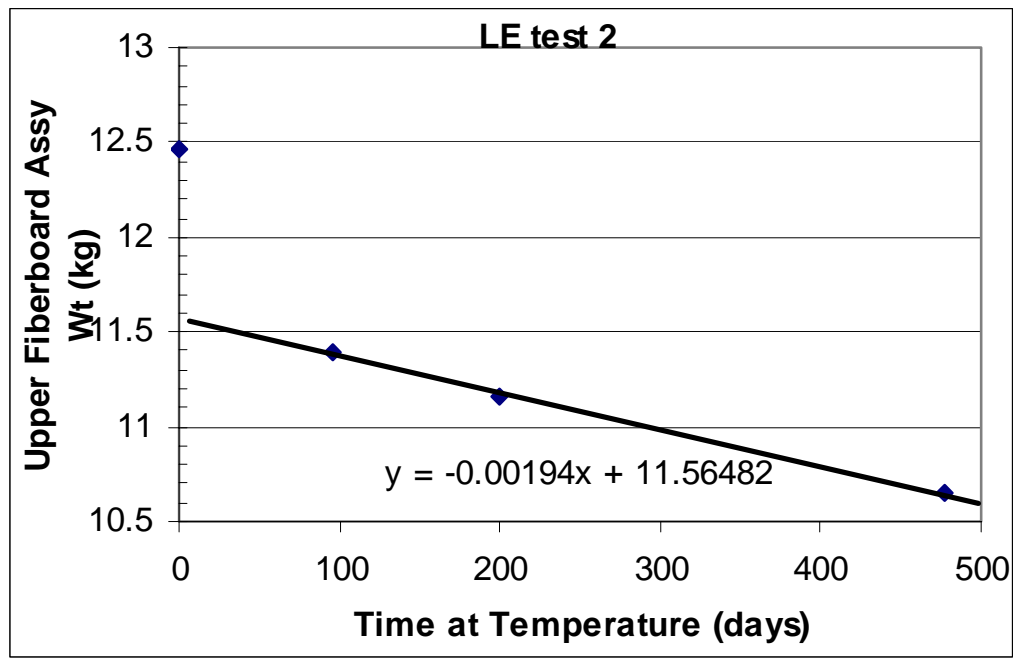

Figure 24. Weight variation for LE2 upper fiberboard assembly. 
CC: D. M. Barnes, 707-C

J. S. Bellamy, 773-41A

K. P. Burrows, 705-K

G. T. Chandler, 773-A

W. L. Daugherty, 773-A

A. DiSabatino, LLNL, Bldg 1677

K. A. Dunn, 773-41A

B. A. Eberhard, 105-K

T. J. Grim, 105-K

E. R. Hackney, 705-K

M. K. Hackney, 705-K

N. C. Iyer, 773-41A

J. W. McClard, 703-H

J. W. McEvoy, 730-4B

T. M. Monahon, 705-K

J. L. Murphy, 773-41A

J. M. Shuler, DOE-HQ EM-63

T. E. Skidmore, 730-A

A.J. Stapf, 717-K

T. M. Stefek, 773-41A

L. E. Traver, 705-K

L. S. Yerger, 705-K

Document Control 